\title{
La protección a los seres sintientes y la personalización jurídica de la naturaleza aportes desde el constitucionalismo colombiano
}

\author{
Protection of sentient beings and legal personalization of nature \\ contribution from the Colombian constitutionalism
}

\author{
Juan Pablo SARmiento E. ${ }^{1}$ \\ Universidad del Norte, Colombia \\ jpsarmiento@uninorte.edu.co
}

\begin{abstract}
Resumen: En los últimos años, distintas experiencias jurídicas han identificado y enriquecido la protección de los animales al reconocerlos como seres sintientes, y de la naturaleza, dándole a ella, personalidad jurídica. No obstante, en este artículo se argumenta que, a pesar de la relevancia de la protección jurídica de la naturaleza, la biodiversidad y los seres sintentes, en realidad no se trata de una ampliación dela carta de derechos constitucionales a quienes no tienen voz; se trata de una reiterada posición jurídica en torno a la protección ecocentrista, que parecería haber surgido en distintos países, con categorías jurídicas disímiles, pero idénticas funciones, y que en realidad, encarnan sentencias estructurales con órdenes complejas de protección. Igualmente, se argumenta que la protección de los seres sintientes y
\end{abstract}

1 Abogado de la Pontificia Universidad Javeriana, Magíster y Doctorado en Derecho de la Universidad de los Andes. Profesor de la Universidad del Norte vinculado al Grupo de Investigación en Derecho y Ciencia Política de la misma Universidad. Director del Grupo de litigio de interés público de la Universidad del Norte.Email: jpsarmiento@uninorte.edu.co, jua-sarm@uniandes.edu.co En este trabajo también recoge algunos resultados de investigación adelantados por Caribe Visible (Boletín 10-13).

Artículo recibido el 19.02.2020 y aceptado para publicación el 05.08.2020. 
los ecosistemas es aún un problema jurídico sin solución autónoma, dependiendo en todos los casos, del vínculo de los derechos fundamentales de seres humanos.

Palabras clave: Seres sintientes, derechos fundamentales de la naturaleza, la naturaleza como sujeto de derecho.

\begin{abstract}
In recent years, various legal experiences have identified and enriched the protection of animals by recognizing them as sentient beings, and of nature, subjecting fundamental rights in it. However, in this article it is argued that, despite the relevance of the legal protection of nature, biodiversity and living beings, it is not really an extension of the charter of constitutional rights to those who have no voice; It is a repeated legal position around ecological protection, which seems to have been operated in different countries, with dissimilar legal categories, but identical functions, and in fact, embody structural sentences with complex orders of protection. Likewise, it is argued that the protection of sentient beings and ecosystems is still a legal problem without an autonomous solution, control in all cases, of the bond of the fundamental rights of human beings.
\end{abstract}

Keywords: Sentient beings, fundamental rights of nature, formalist labyrinth, nature as a subject of law.

\title{
1. Introducción
}

El reconocimiento de la obvia relación y dependencia del ser humano de los ecosistemas y el medio ambiente ha producido recientemente algunas categorías jurídicas que pretenden dar respuesta a la necesaria protección del ecosistema en el que habitamos y del que dependemos, y a la vez, garantizar el desarrollo económico, sin sacrificar la subsistencia y calidad de vida de las generaciones presentes y futuras. De igual forma, distintas categorías jurídicas, que serán descritas y definidas en este trabajo, han ampliado la protección contra la crueldad animal, elevando su reconocimiento en derecho, al crear calidades como seres no humanos "seres sintientes", "animales no humanos" y "seres sintientes con un valor intrínseco".

2 Preliminarmente, podemos señalar que "ser sintiente", así como "animales no humanos", como lo indica la exposición de motivos de la Ley 1774 de 2016 en Colombia, así como las sentencias de la Corte Constitucional y la reforma al Código Civil francés, es un ser vivo dotado de sensibilidad, que si bien no son portadores de 
Como se procederá a demostrar a continuación, esta ola constitucional que reconoce personalidad jurídica a ecosistemas y prohíbe la crueldad contra los animales ha sido un instrumento útil -no por ello eficaz- para la protección de ecosistemas y animales de actividades ilícitas y explotación ilegal de recursos naturales, pero no han conducido a limitar actividades extractivas o productivas intensivas como lo son la ganadería extensiva, los monocultivos, las corridas de toros, la explotación de hidrocarburos y minerales, entre otros.

Para demostrar lo anterior, procederemos a tomar el caso colombiano para ilustrar el argumento antes referido, esto es: la evolución convergente de herramientas jurídicas - personalidad jurídica de ecosistemas y reconocimiento de sintiencia de los animales- para la prohibición de la crueldad contra animales y la personalización jurídica de la naturaleza, por medio del reconocimiento de la sintiencia de los animales y sentencias estructurales de segunda generación ${ }^{3}$ imputándole personalidad jurídica a varios ecosistemas. Con todo, se partirá de la distinción práctica de cada una de ellas, pues se ilustrará cómo las Cortes han profundizado en las sentencias estructurales de segunda generación ${ }^{4}$, cuando se trata de proteger ecosistemas, mientras que ha sido más prudente cuando se trata del amparo de los seres sintientes.

derechos ni cuentan con capacidad de goce y ejercicio, están protegidos contra formas de crueldad, dada, precisamente, la sensibilidad que se les reconoce.

3 Una sentencia estructural está asociada al estado de cosas inconstitucional, donde los jueces identifican la vulneración masiva y generalizada de varios derechos constitucionales que afecta a un número significativo de personas, y es consecuencia de la prolongada omisión de las autoridades en el cumplimiento de sus obligaciones para garantizar los derechos. La Corte Constitucional colombiana ha advertido esta situación a partir de pluralidad de acciones de tutela con el mismo objeto, que buscan garantizar el derecho conculcado, que demuestran la no expedición de medidas legislativas, administrativas o presupuestales necesarias para evitar la vulneración de los derechos. Se llaman sentencias o litigios estructurales en la medida en que advierten que se trata de un problema social cuya solución compromete la intervención de varias entidades, que demanda un esfuerzo presupuestal adicional importante. Ahora bien, el litigio estructural tiene raíces en los cincuenta en Estados Unidos con la sentencia Brown vs. Board of Education de mayo de 1954, que activó una serie de structural remedies. SARAVIa Y RodrígueZ, (2015). p. 123. En este documento, se han llamado sentencias estructurales de segunda generación en la medida en que las cortes no declaran un estado de cosas inconstitucional a raíz de derechos individuales desconocidos masivamente, sino la violación de los derechos de generaciones que están por venir, en una conexidad abierta con la conservaciones de ecosistemas, de manera que, materialmente, imponen obligaciones sistemáticas y estructurales a diversas entidades públicas, competentes en materia ambiental y de orden público, para adoptar acciones afirmativas, no sólo para la conservación del ecosistema, sino para su recuperación, orientado constantemente hacia el principio de solidaridad intergeneracional.

4 Ver ut supra, pie de página 25. 
Para desarrollar este trabajo, se presentará en, primer lugar, aproximaciones a algunos tratados internacionales que enriquecen el "constitucionalismo biocentrico"s, a pesar de la elusiva integración al bloque de constitucionalidad por la Corte Constitucional colombiana (2), para luego entrar a estudiar las decisiones judiciales portadoras de estas herramientas que podrían asimilarse al "constitu-

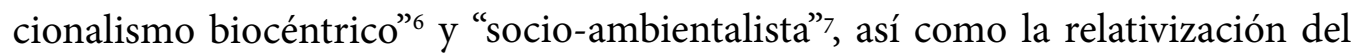
alcance de la protección animal cuando se trata de corridas de toros (3), para luego dar cuenta de aquellas que han brindado personalidad jurídica a ecosistemas completos, en aras de proteger las generaciones futuras, en una alternativa quizá más antropocéntrica limitada a la conexidad con los derechos de las generaciones futuras (4).

\section{El "constitucionalismo biocéntrico" global y los tratados internacionales que lo refuerzan en Colombia}

Colombia cuenta con una abundancia de tratados internacionales y acuerdos, así como la preocupación político-jurídica por la protección al medio ambiente, a la biodiversidad y a la naturaleza. Esta preocupación y tratados han sido clasificadas y explicadas cuando menos, en tres orientaciones conceptuales y, si se quiere ideológicas, a saber: el antropocentrismo, el ecocentrismo y el biocentrismo ${ }^{8}$.

Con todo, gobiernos populistas y las tendencias de izquierda y derecha les han sumado peso ideológico a estas orientaciones, en la medida en que adoptan unas y señalan otras como opuestas y radicales. La consecuencia es evidente, pues esta politización ha eludido consensos respecto a la protección del ambiente y los re-

5 Como se expondrá más adelante, el biocentrismo pretende la conservación radical e inalterable de la naturaleza. Cuando nos referimos al constitucionalismo biocentrico, nos referimos a las reglas y principios constitucionales que se condensan en ciertas experiencias del sur global, aunque no se reducen a ellas, que extendieron ampliamente la protección al ambiente sano y la naturaleza. CARDUCCI y CASTillo (2016), p. 255.

6 Carducci y Castillo (2016), p. 255.

7 Carducci y Castillo (2016), p. 255.

8 El biocentrismo y el antropocentrismo se encuentran en una notable tensión, en tanto, el primero pretende la conservación radical e inalterable de la naturaleza, mientras para el segundo defiende la explotación y comercialización de la tierra sin límites. Se trata de una posición antagonista entre la protección radical de la biósfera y la extracción ilimitada de los recursos naturales para el desarrollo económico. Así, el antropocentrismo supone que la naturaleza es un banco de "recursos naturales" y las especies vivas constituyen "materia prima" industrializable en productos comercializables para obtener utilidades. AgUirRe (2015), p. 237. 
cursos naturales, muy a pesar de evidencias científicas sobre la crisis ambiental, el cambio climático y la extinción masiva de especies.

Quizá por lo antedicho, se ha considerado que el biocentrismo es una corriente contra-hegemónica, desarrollada ampliamente en el derecho "andino", que ha construido un Estado de derecho "socio-ambientalista" y que da origen a un "nuevo constitucionalismo de la biodiversidad". Este "nuevo constitucionalismo", "constitucionalismo biocéntrico", "constitucionalismo experimental" o "constitucionalismo de la alteridad" se cimienta en las constituciones ecuatoriana y boliviana, que explícitamente reconocen a la naturaleza como un sujeto de derechos, pero que por demás, se convierten en centros de producción de derecho, esto es, un sistema jurídico "autóctono", que si bien no se divorcia del ibérico-romano, se separa de éste en tanto produce categorías jurídicas propias ${ }^{10}$.

No obstante, quizá esta descripción esté obviando otra explicación, en tanto su punto de partida entiende que la conciencia jurídica latinoamericana sigue siendo subordinada y una versión deformada de la europea ${ }^{11}, y$, por otro lado, sugiere que el constitucionalismo de la alteridad es un derecho autóctono propio de relaciones socioculturales más próximas a la naturaleza.

Sin embargo, esto no parecería ser cierto, en tanto, Ecuador ${ }^{12}$ y Bolivia ${ }^{13}$ podrían haber iniciado con estos experimentos constitucionales, pero países como Fran$\mathrm{cia}^{14}$, Reino Unido ${ }^{15}$, Australia ${ }^{16}$, Alemania $^{17}$, Austria $^{18}$, Colombia $^{19}$, Costa Rica $^{20}$,

9 Carducci y Castillo (2016), p. 255.

10 Carducci y Castillo (2016), p. 256.

11 ESQUirol (2014).

12 Constitución de la República del Ecuador, 2008. Título VII. Artículos 71, 72 y 73, que identifican a la naturaleza o "Pacha Mama", como titulares del derecho integral a su existencia y el mantenimiento y regeneración de sus ciclos vitales, estructura, funciones y procesos evolutivos, así como derechos afirmativos a su restauración.

13 Ley 71 de 2010, Derechos de la Madre Tierra, Asamblea Legislativa del Estado de Bolivia. Establece el artículo $5^{\circ}$ de la citada norma la titularidad de los derechos a "la Madre Tierra".

14 La ley 2015-177 del 16 de febrero de 2015 reconoce la sintiencia de los animales, con antecedentes en normas que criminalizan el maltrato animal.

15 Animal Welfare Act 2006. Animal Health and Welfare (Escocia) Act 2006.

16 Animal Care And Protection Act 64 2001, reformada en 2019 por Animal Welfare Legislation Amendment Bill 2019.

17 Animal Welfare Act 1998, Federal Law Gazette I, p. 1094, reformado por Animal Welfare Regulation Governing Experimental Animals of 1st August, 2013 (Federal Law Gazette [BGBl]. I pp. 3125, 3126).

18 Animal Welfare Act 2004 (reformado en 2017).

19 La Ley 1774 del 06 de enero de 2016, por medio de la cual se modifican el Código Civil, la Ley 84 de 1989, el Código Penal, el Código de Procedimiento Penal y se dictan otras disposiciones.

20 Asamblea Legislativa de la Republica de Costa Rica, Ley 7451 de 03 noviembre de 1994, Bienestar de Los Animales. 
Argentina $^{21}$, entre otros, desarrollaron otras herramientas jurídicas que prohíben la crueldad contra los animales, condensadas en el reconocimiento a la sintiencia de los animales y sancionando prácticas crueles. Inclusive, otros países reconocieron personalidad jurídica a ecosistemas, como Nueva Zelanda -fue el primer país en reconocer derechos a un río (río Whanganui), en el $2017^{-22}$,e India, -nación que hizo lo propio con los ríos Ganges y Yamuna, en el mismo año- ${ }^{23}$.

En otras palabras, podría tratarse de una evolución convergente ${ }^{24}$ que carece de vasos comunicantes ideológicos, culturas jurídicas dominantes-subordinadas, procesos de neo-colonización o centros de producción y recepción jurídica. Quizá, se trata de un producto de la concientización global por la protección del medio ambiente y el reconocimiento ético de la sensibilidad de ciertos animales, que ha producido reacciones normativas que convergen en categorías jurídicas disímiles nominalmente, pero idénticas funcionalmente. Categorías como "seres no-humanos", "seres sintientes" o simplemente la prohibición de maltrato responden a la misma función: suprimir la crueldad innecesaria con ciertos animales, que se reconocen como "más conscientes" o poseedores de algún grado de autoconciencia, pero conservar la facultad dispositiva que tienen los seres humanos sobre la vida de los animales y extraer productos industrializables objetos de comercio.

Por su parte, el reconocimiento de algunos ecosistemas como sujeto de derecho también ha sido una herramienta extendida en diversas culturas jurídicas que no hacen parte de las mismas familias jurídicas ${ }^{25}$. En efecto, Nueva Zelanda, India y Colombia parecerían tener poco parentesco y vasos comunicantes, pero al enfrentar el mismo problema, deciden reconocer la personalidad jurídica de un

21 Ley 26994 de 2014, Código Civil y de Comercio, con importantes antecedentes, como la Ley 14.346 de 1958, sobre la criminalización del maltrato animal y la Ley 27330 de 2016, sobre prohibición de carreras de perros.

22 Rio Whanganui. Te Awa Tupua (Whanganui River Claims Settlement) Act 2017. Hsiao (2012), p. 371. Ver también el Te Urewera Act 2014, por medio del cual el Parlamento Neozelandes también reconoció como sujeto de derecho a un parque natural.

23 Mohd. Salim vs. State of Uttarakhand \& others (2017), High Court of Uttarakhand at Nainital.

24 La evolución convergente es un término utilizado en la biología y la genética que demuestra que los mecanismos genéticos subyacentes son diferentes en especies relacionadas de forma distante (convergentes), donde distintas especies presentan las mismas adaptaciones como consecuencia de su exposición a ambientes similares. ARENDT y Reznick (2008) "Convergence and parallelism reconsidered: what have we learned about the genetics of adaptation?", en Trends in Ecology and Evolution (No. 23), pp. 26-32.En este texto se toma este concepto para representar las "adaptaciones" similares de categorías e instituciones jurídicas a entornos o contextos idénticos, muy a pesar de pertenecer a familias jurídicas distintas.

25 Kennedy (2006). 
ecosistema, no para protegerle contra la crueldad o por identificar en él sustratos neurológicos. Se trata de la identificación de un problema ambiental de gran magnitud que amenaza la existencia misma del ecosistema y que busca proteger su subsistencia y la de los seres humanos que dependen de él.

Lo mismo podría constatarse de la experiencia y acumulación de tratados internacionales sobre medio ambiente mencionados al inicio de este documento, que, si bien han sido resaltados y han justificado algunas decisiones relevantes en sede de tutela, no han contado con una definición o incorporación explícita por parte de la Corte Constitucional al bloque de constitucionalidad. Muchas de estas herramientas para la protección ambiental se han consignado en instrumentos internacionales, cuya aprobación ha sido transversal en la experiencia latinoamericana y algunos, inclusive globalmente.

Si bien es plausible asegurar que algunos casos han sido exitosos, como el protocolo de Montreal ${ }^{26}$, también es cierto que otros han fallado, tanto en eficacia como en contenido, como lo es el acuerdo de París de $2015^{27}$.La abundante aprobación de tratados internacionales sobre protección al medio ambiente, ha sido descrita por algunos como expresiones del constitucionalismo transformador, constitucionalismos transnacional, o incluso, ius constitutionale commune 28 y que de alguna forma, ha moldeado e impulsado los avances jurídicos que serán objeto de estudio de este documento, de cara a un problema común, tanto regional como global. Colombia no ha sido ajena a la adición de abundantes instrumentos internacionales suscrito sobre la materia ${ }^{29}$.

\footnotetext{
26 SARMiEnTo (2019), p. vi.

27 SARMiento (2018), p. 187.

28 VON BOGDANDY (2015).

29 SARMiento (2018). En Colombia, se han suscrito los siguientes instrumentos internacionales sobre la protección al medio ambiente: La Declaración de Rio sobre el Medio Ambiente y el Desarrollo; La declaración, proclamada el 15 de octubre de 1978, fue aprobada por la Organización de la Naciones Unidas para la Educación, la Ciencia y la Cultura (UNESCO), y posteriormente por la Organización de las Naciones Unidas (ONU); Convención Marco de las Naciones Unidas sobre el cambio climático; Convenio sobre la Diversidad Biológica; Protocolo de Kioto sobre el cambio climático, Convención sobre el comercio internacional de especies amenazadas de fauna y flora silvestres; Protocolo de Cartagena sobre seguridad de la Biotecnología; Convenio Internacional para la protección de las obtenciones vegetales; Convenio de Cartagena sobre la protección y el desarrollo del medio marino en la región del Caribe; Protocolo relativo a la cooperación para combatir los derrames de hidrocarburos en la Región del Gran Caribe; Convenio de Viena para la protección de la capa de ozono; Protocolo de Montreal relativo a las sustancias que agotan la capa de ozono; Convenio de Basilea sobre el movimiento transfronterizo de desechos peligrosos; Convenio marco de cambio climático; Convenio internacional de las maderas Tropicales; Convenio de Rotterdam sobre el procedimiento de
} 
De hecho, la Corte parecería eludir esta incorporación, incluso para tratados emblemáticos y de alto impacto, como el acuerdo de París ${ }^{30}$, Convenio de Minamata sobre el mercurio ${ }^{31}$, a excepción indirecta del principio de precaución consignado en la Declaración de Río de 1992, que quizá no supone el reconocimiento y jerarquización del derecho internacional ambiental al bloque de constitucionalidad en Colombia, pues para la Corte, dicho principio ya se encontraba incorporado en la Constitución y la Declaración de Río sólo brinda elementos para su interpretación ${ }^{32}$.

\section{Seres sintientes: entre la concientización global y la resistencia}

Como se mencionó previamente, diversas experiencias han dado cuenta del reconocimiento de la personalidad jurídica a ecosistemas y la protección de los animales contra la crueldad. Colombia también ha reconocido personalidad jurídica a varios ecosistemas: río Atrato, páramo de Pisba, la Amazonía, el río Cauca, río Magdalena, río Quindío, Parque Nacional Natural los Nevados y el Parque Vía Isla Salamanca. Así mismo, cuenta con una nutrida producción jurisprudencial y varias leyes que han procurado la protección de los animales y su reconocimiento como seres sintientes.

El reconocimiento de personalidad jurídica de un ecosistema supone considerarlo como organismo vivo "dado que el medio ambiente y toda forma de vida que lo compone está dotado de por sí y ante sí, de ciertas prerrogativas autónomas" según ha expresado una de las sentencias que entregó personalidad jurídica al Parque Isla Salamanca. Esto quiere decir, define la Corte, que el ecosistema tiene derechos, y que se espera que el accionar de las instituciones a partir de la declaratoria, salvaguarde la vida de su ecosistema, y en efecto, no afecte la de las personas. Comprende al hombre, la flora y la fauna, en un "plano igualitario e

consentimiento fundamentado previo aplicable a ciertos plaguicidas y productos químicos en el comercio internacional; Convenio de Estocolmo sobre los contaminantes orgánicos persistentes - POPS, entre otros

30 Proceso de revisión previa de constitucionalidad de la Ley 1844 de 2017 "por medio de la cual se aprueba el "Acuerdo de París" (2018), Sentencia C-048. Corte Constitucional.

31 Proceso de revisión de constitucionalidad de la Ley 1892 de 2018, por medio de la cual se aprueba el "Convenio de Minamata sobre el Mercurio", hecho en Kumamoto (Japón) el 10 de octubre de 2013. (2019), Sentencia C-275. Corte Constitucional.

32 Juan Gabriel Rojas López (2010), Acción Pública de Inconstitucionalidad, Sentencia C-595, Corte Constitucional.Andrés Rodríguez Pizarro, (1994), Acción Pública de Inconstitucionalidad, Sentencia C-528, Corte Constitucional. Ver también Acevedo (2016). 
interdependentista, en el que se cohesionan para hacer llevadera la vida de todos en La Tierra, de donde se sigue que deben propender armónicamente por evitar la degradación del medio ambiente, la contaminación del aire, la extinción de especies animales, la sequía de las cuencas hídricas, las enfermedades colectivas (pandemias) y todo el impacto negativo que produce el uso desmedido, descontrolado, abusivo e inadecuado de los denominados recursos naturales" ${ }^{33}$.

Sin embargo, al tratarse de seres sintientes, las Cortes colombianas no han llegado hasta la personalización jurídica, y han concentrado la protección de los animales como seres sintientes, proscribiendo la crueldad contra ellos. La principal ruta que ha recorrido el sistema jurídico colombiano para el reconocimiento de la protección jurídica de los seres sintientes ha sido la jurisprudencia constitucional. Si bien la Constitución colombiana ha sido llamada una constitución "ecológica", debido a que cuenta con una batería de instrumentos que reconocen y protegen derechos a la conservación ambiental, desarrollo sostenible y biodiversidad, no cuenta con una declaración explícita de la naturaleza como sujeto de derecho ${ }^{34}$.

\subsection{Las corridas de toros, corralejas y riñas de gallos, el laberinto formalista que atenúa la protección animal}

La Corte Constitucional, a partir de demandas de inconstitucionalidad y algunas acciones de tutela promovidas en defensa de los "derechos de los animales", ha extendido un importante marco de sub-reglas para la interpretación y prohibición de la crueldad contra los seres sintientes.

No obstante, la principal causa jurídica que ha movilizado el aparato judicial ha sido el estatuto de protección animal, que contemplan la excepción de la prohibición de crueldad a prácticas culturales como las corridas de toros, las corralejas,

33 Luís Miguel Llorente (Grupo de Litigio de Interés Público de la Universidad del Norte Vs. Ministerio de Ambiente y Desarrollo Sostenible (MADS), a la Unidad Administrativa Especial de Parques Nacionales Naturales, a la Procuraduría General de la Nación, a la Fiscalía General de la Nación, a la Policía Nacional de Colombia y otros (2020), Corte Suprema de Justicia, Sala de Casación Civil.

34 Antes de década de los noventas el derecho ambiental colombiano todavía era muy incipiente, fue con la Constitución Política de 1991, que se logró incorporar la dimensión ambiental en el ideario político. Con la Constitución de 1991, el tema ambiental alcanza su máxima jerarquía jurídica. En ésta se consagraron aproximadamente 50 disposiciones que se relacionan directa o indirectamente con el tema ambiental. En últimas, ha sido un hecho reiterado por la Corte Constitucional que, Colombia, en materia ambiental, su Constitución Política hace gala de uno de los sistemas más completos que para la protección del mismo han producido los Estados constitucionales modernos, así, es también conocida como, "Constitución Verde" o "Constitución Ecológica”. SÁNCHEZ, (2002). 
las becerradas, las novilladas, el rejoneo, las tientas y las riñas de gallos. Como se señaló previamente, el legislador ha contribuido con la construcción de herramientas de protección animal desde hace varios años en Colombia. Las normas más relevantes sobre la materia son la ley 84 de $1989^{35}$ y la ley 1774 de $2016^{36}$. En ambas normas se dispone de una serie de sanciones y competencias para garantizar el bienestar animal y la protección contra la crueldad. Inclusive, la ley $1774 \mathrm{de}$ 2016 penaliza la crueldad contra los animales.

Sin embargo, en las dos normas se plantearon excepciones en torno a las actividades antes citadas, entendiendo que se trataba de expresiones culturales objeto de protección. Quizá, la tauromaquia ha sido la actividad que más ha incentivado este debate tanto por su relevancia económica y política, como por la infraestructura pública que está destinada para ello en ciertas ciudades como Bogotá, Cali, Medellín y Manizales.

Estas normas son entonces las que han provocado el pronunciamiento judicial, con oscilaciones en los juicios de ponderación que han intentado mediar entre el reconocimiento de tradiciones y prácticas culturales, y la protección de la fauna, y el reconocimiento de los animales como "seres sintientes" en Colombia. La siguiente tabla permitiría identificar la posición asumida por la Corte Constitucional en torno a este problema jurídico, y resolvería el siguiente problema jurídico:¿Las prácticas culturales son excepciones proporcionales y razonables al deber de protección contra el maltrato animal de los seres sintientes que sólo se pueden restringir por el legislador?

Los fallos más relevantes en esta materia fueron las sentencias $\mathrm{C}-1192$ de 2005 , C-115 de 2006, C-367 de 2006, C-666 de 2010, C-889 de 2012, C-283 de 2014, C-467 de 2016, C-041 de 2017, Auto 547 de 2018 y SU-056 de 2018.

35 Esta ley contiene el "Estatuto de protección animal", y establece medidas de protección contra el sufrimiento y el dolor, causados directa o indirectamente por el hombre. Establece también deberes con los animales, normas en torno a la experimentación médica y científica y reglas en torno al sacrificio animal con fines distintos al consumo.

36 El objeto de la ley 1774 de 2016, es reconocer los animales como seres sintientes, establecer reglas de protección contra el sufrimiento y el dolor, tipifica como delitos algunas conductas relacionadas con el maltrato a los animales, y se establece un procedimiento sancionatorio de carácter policivo y judicial. 


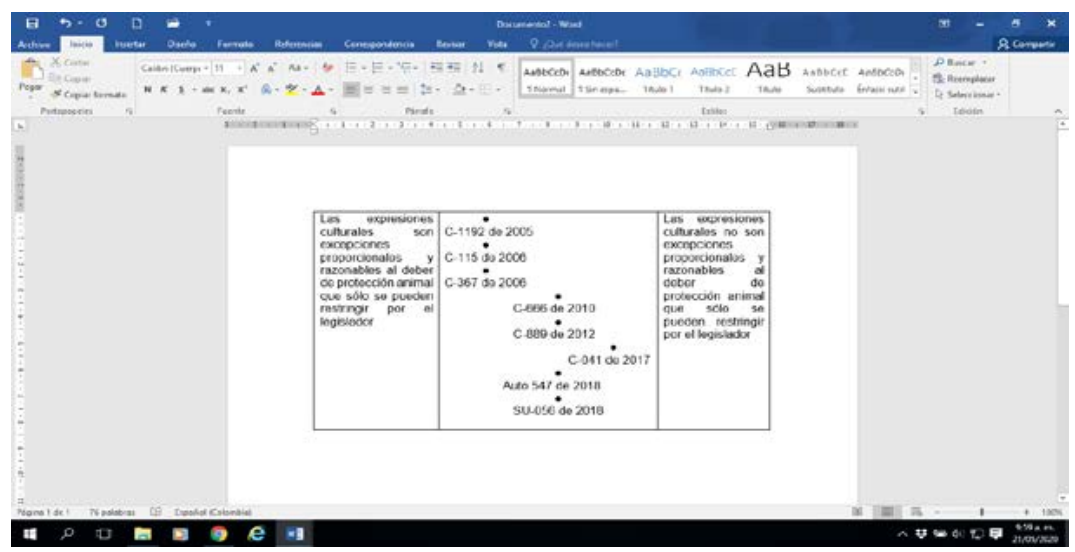

La sentencia C-1192 de $2005^{37}$ conoció de una demanda de inconstitucionalidad contra los artículos $1^{\circ}$ (espectáculos taurinos como expresión artística), $2^{\circ}$ (aplicación general del reglamento), 22 (ingreso de menores de 10 años, comportamiento durante la lidia) y 80 (fomento de fiestas taurinas) parciales de la Ley 916 de 2004 "Por la cual se establece el Reglamento Nacional Taurino". En esta sentencia, la Corte reconoció que las corridas de toros, las corralejas, las becerradas, las novilladas, el rejoneo, las tientas y las riñas de gallos, son una tradición artística y cultural de Colombia. Por esta razón, protegió dichas expresiones culturales a pesar de suponer tratos crueles con los animales.

Por su parte, la sentencia C- 115 de $2006^{38}$ resolvió una demanda de inconstitucionalidad contra los artículos $1^{\circ} ; 2^{\circ} ; 12$ (niños torerillos); 22; 26 (espectáculos presidido por Alcaldes); 31, (ganadería producto de alto interés nacional) y nuevamente, el artículo 80 de la ley 916 de 2004. En este caso, la Corte declaró la constitucionalidad de la expresión "la regulación de la preparación, organización y desarrollo de los espectáculos taurinos y de las actividades relacionadas con los mismos", contenida en el artículo $1^{\circ}$. de la ley 916 de 2004. Igualmente, confirmó lo resuelto en la Sentencia C-1192 de 2005, en relación con las expresiones "Los espectáculos taurinos son considerados como una expresión artística del ser humano". No obstante, declaró la constitucionalidad de la expresión "La que forman

37 Ángela Viviana Bohórquez Cruz (2005), Acción Pública de Inconstitucionalidad, Sentencia C-1192, Corte Constitucional.

38 Mónica Beltrán Espitia (2006) Acción Pública de Inconstitucionalidad, Sentencia C-115, Corte Constitucional. 
con niños torerillos [...] del mundo taurino”, del artículo 12 de la Ley 916 de 2004, salvo la expresión "profesionales ... cuando su precocidad permite su explotación económica" la cual fue declarada inexequible.

La expresión declarada exequible queda condicionada al entendido que los niños torerillos únicamente podrán hacer parte de una cuadrilla cuando hayan cumplido los catorce (14) años de edad y, por otra parte, declara la inconstitucionalidad del artículo 26, que establecía que la presidencia de los espectáculos taurinos corresponderá al Alcalde de la localidad. Declara la constitucionalidad del parágrafo del artículo 31 de la ley 916 de 2004, salvo las expresiones "son producto de alto interés nacional, dada su importancia que" y "todos los", las cuales son inexequibles.

El aporte más relevante de la sentencia citada es que declara la inexequibilidad parcial del artículo 80 de la ley demandada, del "fomento de" la tauromaquia y se excluye la posibilidad de que el Estado patrocine el sostenimiento de las escuelas taurinas. En otras palabras, esta sentencia insiste en la prohibición de las entidades públicas de financiar este tipo de actividades.

Ahora bien, la sentencia C-666 de $2010^{39}$ resolvió la demanda de inconstitucionalidad contra el artículo $7^{\circ}$ (exceptúa el rejoneo, coleo, las corridas de toros, las novilladas, corralejas, becerradas y tientas así, como las riñas de gallos, del régimen contra el maltrato animal) de la ley 84 de 1989 "por la cual se adopta el estatuto nacional de protección de los animales y se crean unas contravenciones". Como se verá más adelante, este es el caso de mayor importancia y se convierte en el eje de esta línea jurisprudencial, pues con este fallo, la Corte declaró su falta de competencia para regular la protección de los animales, puesto que ésta es una competencia del Congreso de la República.

La Corte declaró la constitucionalidad condicionada del artículo $7^{\circ}$ de la Ley 84 de 1989 que tiene la excepción que permite la realización de rejoneo, coleo, las corridas de toros, las novilladas, corralejas, becerradas y tientas, pero reitera la prohibición de las entidades públicas de patrocinar o facilitar recursos públicos para su realización ${ }^{40}$. Todo lo anterior, para concluir que la regulación que expi-

39 Carlos Andrés Echeverry Restrepo (2010) Acción Pública de Inconstitucionalidad, Sentencia C-666, Corte Constitucional.

40 La Corte condicionó la constitucionalidad de la citada norma en el siguiente sentido: "1) Que la excepción allí planteada permite, hasta determinación legislativa en contrario, si ello llegare a ocurrir, la práctica de las actividades de entretenimiento y de expresión cultural con animales allí contenidas, siempre y cuando se entienda que estos deben, en todo caso, recibir protección especial contra el sufrimiento y el dolor durante 
da el legislador debe tener en cuenta el deber de protección a los animales y, en consecuencia, contener una solución que de forma razonable lo armonice en este caso concreto con los principios y derechos que justifican la realización de dichas actividades consideradas como manifestaciones culturales. Con este propósito, dicha regulación deberá prever protección contra el sufrimiento y el dolor de los animales empleados en estas actividades y deberá propugnar porque en el futuro se eliminen las conductas especialmente crueles para con ellos.

La Corte remite al Congreso el deber de ajustar estas prácticas, en ejercicio de su libertad de configuración normativa, que inclusive podría llegar a prohibir las manifestaciones culturales que implican maltrato animal, si considera que debe primar el deber de protección sobre la excepcionalidad de las expresiones culturales $^{41}$.

Por su parte, la sentencia C-889 de $2012^{42}$ resolvió la demanda de inconstitucionalidad contra los artículos 14 (autorización previa para la celebración de espectáculos taurinos) y 15 (comunicación de la realización de espectáculos) ambos parciales de la Ley 916 de 2004. También accionó los requisitos que deben ser verificados por las autoridades locales para autorizar los espectáculos taurinos en plazas de toros permanentes e itinerantes.

Como se constata, las sentencias antes citadas dan cuenta de un avance hacia la protección de tratos crueles a los seres sintientes. Con todo, la sentencia más progresista fue la C-041 de $2017^{43}$. En este fallo, la Corte decidió la acción pública de inconstitucionalidad que se inició contra la Ley 1774 de 2016 que, entre otras reglas, adicionó el título XI-A, "De los delitos contra los animales", al Código Penal,

el transcurso de esas actividades. En particular, la excepción del artículo 7 de la ley 84 de 1989 permite la continuación de expresiones humanas culturales y de entretenimiento con animales, siempre y cuando se eliminen o morigeren en el futuro las conductas especialmente crueles contra ellos en un proceso de adecuación entre expresiones culturales y deberes de protección a la fauna. 2) Que únicamente podrán desarrollarse en aquellos municipios o distritos en los que las mismas sean manifestación de una tradición regular, periódica e ininterrumpida y que por tanto su realización responda a cierta periodicidad; 3 ) que sólo podrán desarrollarse en aquellas ocasiones en las que usualmente se han realizado en los respectivos municipios o distritos en que estén autorizadas; 4) que sean estas las únicas actividades que pueden ser excepcionadas del cumplimiento del deber constitucional de protección a los animales; y 5) que las autoridades municipales en ningún caso podrán destinar dinero público a la construcción de instalaciones para la realización exclusiva de estas actividades".

41 Sarmiento (2020).

42 Jonathan Ramírez Nieves (2012) Acción Pública de Inconstitucionalidad, Sentencia C-889, Corte Constitucional.

43 María Cristina Pimiento Barrera, Esperanza Pinto Flórez y Juliana Marcela Chahín del Río, (2017), Acción Pública de Inconstitucionalidad, Sentencia C-041, Corte Constitucional. 
conservando la excepción a las actividades de rejoneo, coleo, corridas de toros, novilladas, corralejas, becerradas, tientas, riñas de gallos y los procedimientos utilizados en estos espectáculos por considerarlas culturales. Luego de una extensa exposición de las razones por las cuales, las prácticas crueles y el espectáculo que se puede derivar de ellas se estarían superando, la Corte decidió dar un paso definitivo relativo a la tauromaquia.

La Corte señaló “[1]a dogmática dinámica y evolutiva impone avanzar con mecanismos más decisivos para la efectividad de los intereses de los animales, al disponer hoy de nuevos estudios científicos y mayores saberes. Es un imperativo repensar posibles horizontes y transformar las sedimentadas tradiciones cuando socavan intereses vitales y primarios de toda sociedad democrática y constitucional", y de esta forma, declaró inexequible el parágrafo $3^{\circ}$ previsto en el artículo $5^{\circ}$ de la Ley 1774 de 2016, que adicionó el artículo 339B al Código Penal, esto es, la excepción al delito de maltrato animal que protegen las prácticas de rejoneo, coleo, las corridas de toros, novilladas, corralejas, becerradas y tientas, así como las riñas de gallos y los procedimientos utilizados en estos espectáculos. No obstante, el fallo resolvió el asunto con una exhortación al Congreso de la República ${ }^{44}$.

Con todo, por medio del Auto 547 de $2018^{45}$, la Corte declaró la nulidad de la sentencia C-041 de 2017. En este auto, la Corte considera que en el fallo del 2017 desconoció el precedente consignado en las sentencias C-666 de 2010 y C-889 de 2012. En el marco de este eje jurisprudencial, la Corte Constitucional emitió la sentencia SU-056 de $2018^{46}$.

En este fallo la Corte tomó una decisión en dos sentidos: primero, decidió por vía de tutela, la constitucionalidad de la consulta popular que el Alcalde de Bogotá quería realizar en agosto de 2017 (Decreto Distrital 355 y Decreto Distrital 247 de 2017) sobre la prohibición de las corridas de toros en la ciudad de Bogotá D.C.; segundo, la competencia del Distrito de Bogotá, como autoridad territorial, para ejecutar dicho mandato, en el caso en que efectivamente el voto popular hubiese tomado la decisión de prohibir las corridas de toros en la ciudad.

44 Sarmiento (2020).

45 Daniel Fernando Gutiérrez Hurtado y Juan Pablo OsorioMarín (2018) Solicitud de nulidad de la Sentencia C-041 de 2017, Auto 547, Corte Constitucional.

46 Ramsés Alberto Ruiz Sánchez y otros Vs. el Tribunal Administrativo de Cundinamarca, Sección Primera, Subsección A (2018), Acción de tutela, Sentencia SU-056, Corte Constitucional. 
Para la Corte, ninguna de las dos situaciones es constitucionalmente permisible. En concreto, el Tribunal consideró que el funcionario que convoca a una consulta popular debe tener la competencia de ejecutar la decisión del electorado pues éste constituye un mandato popular, y esto no ocurre en el caso bajo examen, en la medida en que la autorización para realizar las corridas de toros en Bogotá viene expresamente dada por el legislador y el órgano administrativo no juega ningún papel en su autorización o prohibición, en el marco de lo dispuesto por la Sentencia C-666 de $2010^{47}$.

\subsection{El desarrollo paralelo y progresivo de la protección a los seres sintientes}

Ahora bien, paralelamente a la anterior línea jurisprudencial, encontramos otras discusiones en torno a la protección animal, inclusive como derecho fundamental. La Corte utilizó varias categorías jurídicas para responder a la misma función, tales como "seres sintientes", "animales no humanos" y "seres sintientes con un valor intrínseco" ${ }^{4}$. Las diferencias parecen sutiles, pero da cuenta de que el peso abstracto de protección constitucional de los seres sintientes es inferior al de las expresiones culturales. Empero, la protección directa de acciones de maltrato y crueldad, permiten una acción judicial directa por vías ordinarias, como la acción popular.

Lo antedicho puede evidenciarse en la siguiente línea jurisprudencial, que se construyó a partir del patrón fáctico señalado responde al siguiente problema jurídico: ¿Son los animales portadores de derechos fundamentales y protección a formas de maltrato?. Esta Línea jurisprudencial identifica acciones de tutela y habeas corpus, presentadas por individuos, que pretenden la protección de animales en situaciones de maltrato extremo, así como la revisión constitucional de normas. La línea jurisprudencial:

47 Carlos Andrés Echeverry Restrepo (2010) Acción Pública de Inconstitucionalidad, Sentencia C-666, Corte Constitucional.

48 Ver ut supra pie de página 2. 


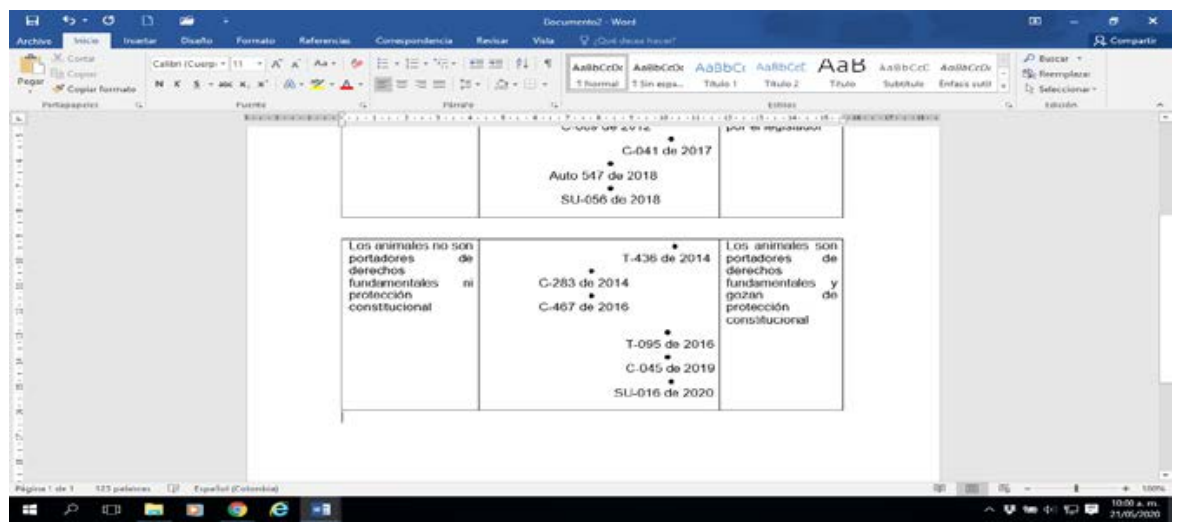

Lo primero que tenemos que destacar es que, en ninguna de las sentencias citadas, la Corte ha reconocido derechos fundamentales a los animales. Como se expondrá, la Corte ha utilizado las categorías jurídicas de animales no humanos y seres sintientes, para construir una obligación constitucional de protección contra el maltrato, pero ha sido reiterativa y cuidadosa en no reconocer a los animales como portadores de derechos fundamentales.

El fallo C-283 de $2014^{49}$ resolvió una demanda de inconstitucionalidad contra los artículos $1^{\circ}$ (prohibición de animales en circos), $2^{\circ}$ (restricción de emisión de licencias) y $3^{\circ}$ (adecuación de los espectáculos circenses) de la Ley 1638 de 2013. En este asunto, sin embargo, la Corte declaró la constitucionalidad de la ley que prohíbe el empleo de animales en los espectáculos circenses. En este caso, la Corte ponderó entre el respeto a los derechos al trabajo, la libertad de escoger profesión u oficio, el libre desarrollo de la personalidad y la libertad de empresa e iniciativa privada de los trabajadores y propietarios de los circos, y la protección de los animales silvestres en la garantía de la preservación del medio ambiente (deberes constitucionales).

La sentencia T-436 de $2014^{50}$ contiene de una importante cantidad de argumentos y reflexiones en torno al reconocimiento del deber constitucional de protección de los animales. En este caso, el accionante pretendía la protección de la leona "Nala", un animal silvestre propiedad de un circo, cuyas condiciones de

49 Guillermo Francisco Reyes González, Pedro Alejandro López Arroyave y Manuel Antonio Avella Mendoza, (2014) Acción Pública de Inconstitucionalidad, Sentencia C-283, Corte Constitucional.

50 Juliana Morad Acero y otros, Vs. la Secretaría Distrital de Medio Ambiente de Bogotá, (2014), Acción de tutela, Sentencia T-436, Corte Constitucional. 
salud y encierro ponían en riesgo su vida y carecían de algún nivel de "dignidad"51. La Corte se encuentra, como se evidenció en la anterior línea jurisprudencial, ante un silencio constitucional relativo a los animales como seres sintientes o una prohibición explícita del maltrato. Para resolver este vacío, la Corte acude al deber del artículo 79 de la Constitución, relativo a la conservación de la flora y fauna. Así, la Corte de entrada, señala que "el asunto bajo revisión se inclina más a buscar la garantía del derecho fundamental al medio ambiente en relación con la protección de la fauna que lo compone", e insinúa que el proceso debería orientarse a la protección de derechos colectivos, como el medio ambiente.

Sin embargo, la decisión va más allá, pues otorga un lapso de dos años para que el legislador prohíba el uso de animales en sus espectáculos, y ordena a la Secretaría Distrital de Ambiente, para intervenir de cara a que la leona Nala sea protegida de su dueño y de las condiciones "hostiles que atenten contra su vida e integridad física”. En este fallo, la Corte vincula el concepto de dignidad que se concreta en la interacción de las personas y éstas con los animales, en tanto éstos tienen la capacidad de sentir. Esta sentencia toma como precedentes los fallos C-1192 de 2005, C-666 de 2010 y C-283 de $2014^{52}$, recordando que "la relación de los seres

\footnotetext{
51 Esta decisión judicial es producto de años de litigio como consecuencia de la crueldad y rigurosidad de las condiciones de confinamiento del animal. El conflicto inicia el 11 de noviembre de 2008 cuando "la Secretaría de Ambiente de Bogotá realizó una visita técnica a las instalaciones del circo, donde observaron que “a 'Nala' y a su hermano 'Pumba' los mantenían en jaulas oxidadas y deterioradas, con disponibilidades de espacios muy reducidas, expuestos a la intemperie, con heridas y procesos de cicatrización en diferentes partes de la cabeza y con comportamientos estereotipados que evidenciaban traumatismos psicológicos agudos". Como consecuencia, la Dirección Legal Ambiental de la Secretaría de Ambiente de Bogotá, en Resolución No. 5402 del 17 de diciembre de 2008, resolvió abrir investigación administrativa sancionatoria de carácter ambiental al señor Orlando Valencia Cataño, en calidad de propietario del Circo Nacional Los Muchachos. Asimismo, como medida preventiva, ordenó el decomiso de los dos leones africanos. En Resolución No. 4527 del 21 de julio de 2009, la Secretaría Distrital de Ambiente resolvió declarar responsable al señor Orlando Valencia Cataño, por incumplir lo preceptuado en la Ley 84 de 1989. En consecuencia, decomisó definitivamente los dos leones africanos, entregándolos en custodia al Parque Zoológico Jaime Duque. El león Pumba fue trasladado al zoológico de Barranquilla, donde finalmente falleció. El dueño del circo inició el trámite administrativo y judicial para conseguir la nulidad de los actos sancionatorios de la Secretaría. Como consecuencia de ello, el 27 de abril de 2012, el Juzgado 14 Administrativo de Descongestión del Circuito de Bogotá negó las pretensiones de la demanda incoada por el señor Orlando Valencia, pero el Tribunal Administrativo de Cundinamarca profirió sentencia el 22 de abril de 2013, mediante la cual declaró la nulidad de las resoluciones 5402, 4527 y 2831, ordenando a la Secretaría de Ambiente de Bogotá adelantar las gestiones necesarias para devolver la única leona sobreviviente a su propietario.

52 Ángela Viviana Bohórquez Cruz (2005), Acción Pública de Inconstitucionalidad, Sentencia C-1192, Corte Constitucional.

Carlos Andrés Echeverry Restrepo (2010) Acción Pública de Inconstitucionalidad, Sentencia C-666, Corte Constitucional.
} 
humanos con los animales no puede ser vertical, de modo que estos últimos sean vistos como meros instrumentos para beneficio de los primeros".

De acuerdo a las evidencias recaudadas, la Corte finalmente reconoció los deberes de protección sobre la leona Nala, pero, dado que ya había un fallo de otra instancia que ordenó la devolución del animal al propietario, ordenó a la Secretaría Distrital de Medio Ambiente de Bogotá, en razón a su función de control y vigilancia del cumplimiento de las normas de protección ambiental, hacer cumplir, dentro del plazo de dos años que el artículo $3^{\circ}$ de la Ley 1638 de 2013 otorga a los circos, para adecuar sus espectáculos sin el uso de especies silvestres o exóticas, vigile permanentemente que la leona Nala no sea objeto de malos tratos o se encuentre en condiciones hostiles que atenten contra su vida e integridad física.

La citada sentencia se dio sin embargo, luego de una trascendental sentencia del Consejo de Estado ${ }^{53}$, en el marco de la mencionada acción popular. Para este caso, el asunto procesal no resultó relevante, pues la acción que se interpuso es la acción que protege los intereses colectivos, entre ellos, la conservación de la flora y la fauna. En este caso fueron demandados la Fundación Instituto de Inmunología de Colombia "FIDIC", el Ministerio de Ambiente y Desarrollo Sostenible, la Corporación para el Desarrollo Sostenible del Sur de la Amazonia "Corpoamazonia", y la Procuraduría General de la Nación, dado el permiso para el estudio con fines de investigación científica otorgado al FIDIC, que suponía la captura y experimentación con alternativas médicas para la malaria,con la especie Aotus nancymaae ar. En esta acción se pretendía proteger la seguridad y salubridad pública, y la efectividad del equilibrio ecológico y el manejo y aprovechamiento racional de los recursos naturales, su desarrollo sostenible, su conservación, restauración o sustitución.

El Consejo de Estado, en una extensa sentencia, recorrió los argumentos relativos a la procedibilidad de la acción popular como mecanismo que podía conducir a la revocatoria de un acto administrativo (permiso), así como diversos principios constitucionales e internacionales relativos a la protección al medio ambiente. Sin embargo, el valor del fallo reside en dos reflexiones.

Guillermo Francisco Reyes González, Pedro Alejandro López Arroyave y Manuel Antonio Avella Mendoza, (2014) Acción Pública de Inconstitucionalidad, Sentencia C-283, Corte Constitucional.

53 Ángela María Maldonado Rodríguez y otros Vs. Ministerio de Medio Ambiente, Fundación Instituto de Inmunología de Colombia y otros (2013), Consejo de Estado, Sala de lo Contencioso Administrativo, Sección Tercera - Subsección C. 
En primer lugar, tacha al "humanismo" como corriente que niega cualquier dignidad a los animales y el medio ambiente - atributo exclusivo del ser humano- y, por lo tanto, niega la titularidad de derechos a los animales y el medio ambiente. El "humanismo" tendría como antónimo "el animalismo" o la defensa de los derechos de los animales, considerando a ésta como una postura minoritaria, ya que la cultura hegemónica parte del reconocimiento exclusivo de derechos a favor de las personas.

Como consecuencia de los anteriores argumentos, el Consejo de Estado le ordenó a la Corporación para el Desarrollo Sostenible del Sur de la Amazonia (Corpoamazonia) revocar las resoluciones 028 del 13 de mayo y 0632 del 29 de junio de 2010 de que otorgaba permiso de estudio de diversidad biológica e investigación científica a la Fundación Instituto de Inmunología de Colombia, FIDIC, de primates en la cuenca del río Amazonas en el Trapecio Amazónico Colombiano. Aunque en este caso, el Consejo de Estado parecería reconocer los derechos de generaciones futuras sobre la biodiversidad, retrocede al momento de reconocer la personalidad jurídica de la especie o los animales objeto del litigio. Por ello, como se argumentará en el segundo título, la personalidad jurídica de la ecosistemas es posible, en el estado actual de cosas, sólo cuando se vincule con los derechos de los seres humanos -presentes y por nacer-.

Posteriormente, la Corte Constitucional expidió la sentencia C-467 de 201654, que resolvió una acción pública de inconstitucionalidad contra la Ley 1774 de 2016, en lo referido a la reforma que hizo del Código Civil, donde declaró a los animales como seres sintientes. Para el accionante, el legislador debió haber ido más allá a partir de instrumentos internacionales ratificados en Colombia, y declarar a los animales como sujetos de derecho.

En esta ocasión, la Corte declaró la exequibilidad de las disposiciones acusadas, porque "si bien es cierto en ellas se alude a los animales como a bienes jurídicos e incluso se emplea la palabra cosas en relación con ellos, también lo es que tal realidad no se opone a la consideración de los animales como seres sintientes dignos de protección contra el maltrato". En este sentido, la Corte reiteró lo señalado, considerando que las modificaciones que introdujeron con la aprobación de la Ley 1774 de 2016, en la que se cambió el contenido normativo del artículo 655

54 Ricardo María Cañón, actuando en su calidad de Personero de Bogotá D.C. (2016), Acción Pública de Inconstitucionalidad, Sentencia C-467, Corte Constitucional. 
del Código Civil, reconoce la calidad de los semovientes como seres sintientes, suponían un margen adecuado de protección para los animales.

La sentencia, aunque negó las pretensiones de la demanda, señaló que en la Constitución subyace un deber de protección a los animales en su condición de seres sintientes, que supone un límite derivado de la función ecológica de la propiedad mediante la cual se prohíben tratos crueles a los animales.

En esta línea jurisprudencial, la Sentencia T-095 de $2016^{55}$ reitera lo señalado en los fallos anteriores, con dos consideraciones adicionales. En primer lugar, se trata de una acción de tutela, y por ello, revisa la titularidad de derechos fundamentales en los seres sintientes. Segundo, realiza consideraciones en torno a la procedencia de este medio de control, teniendo en cuenta la inmediatez y la ausencia de otros medios judiciales que logren la tutela efectiva de derechos, o cuando menos, la protección de maltrato de los seres sintientes.

En este punto la Corte se encuentra nuevamente con el obstáculo de carencia de peso abstracto en la medida en que la Constitución colombiana no tiene una regla o principio legislado en el reconocimiento de seres sintientes o "animales no humanos”. Para obtener dicho principio y reconocer el deber de protección sobre los animales, la Corte acude al concepto de medio ambiente, el deber de protección de la diversidad de flora y fauna y su integridad, la protección a los recursos y "el valor de la dignidad humana como el fundamento de las relaciones entre los seres humanos y estos con la naturaleza y los seres sintientes"; De esta triada la Corte extrae un deber constitucional de protección del bienestar animal, aunado al principio de la solidaridad.

De esta manera, la Corte continúa siendo muy cuidadosa y reiterativa, y resume su línea jurisprudencial en torno a la protección animal en tres ejes: (i) protege la tenencia de animales domésticos por parte de sus propietarios, pero impone obligaciones de cuidado, respeto y salubridad, derivadas de normas del Estatuto de Protección Animal; (ii) la prohibición de tenencia y explotación de animales silvestres y, (iii) protección al bienestar animal, que conlleva a obligaciones tanto para el Estado como para los individuos, de proteger el medio ambiente y con ello, a los seres sintientes. Sin embargo, ha aclarado la Corte, ese mandato constitucional no supone el reconocimiento de un "derecho al bienestar animal, ni la funda-

55 Henry Acuña Cordero Vs. la Personería Local de Fontibón, la Alcaldía Local de Fontibón, la Secretaría Distrital de Salud, el Centro de Zoonosis y la Secretaría Distrital de Ambiente de Bogotá, (2016), Acción de tutela, Sentencia T-095, Corte Constitucional. 
mentabilidad del mismo, ni mucho menos la exigibilidad por medio de la acción de tutela". A diferencia de lo que ocurre con los ecosistemas, la ausencia de un nexo de dependencia o de mutualismo entre el ser humano -presente o por nacer- con el animal, ha impedido que se reconozca personalidad jurídica al animal, limitando el alcance del mandato jurisprudencial a la protección de la crueldad.

Quizá, un aporte dentro de la ratio decidendi del fallo comentado es el recorrido que realiza en tratados internacionales para integrar un bloque de constitucionalidad "ambiental" que identifica los deberes del Estado colombiano de proteger el derecho al ambiente sano y biodiversidad. Sin embargo, la Corte repasa las obligaciones internacionales del Estado consignadas, entre otros, en el Pacto Internacional de Derechos Económicos, Sociales y Culturales, la Observación General No. 14 del Comité de Derechos Económicos, Sociales y Culturales, la Convención Ramsar, la Resolución 45 de 1994 de la Asamblea General de las Naciones Unidas, e inclusive, de la Declaración Universal de los Derechos de los Animales y el Convenio sobre la Diversidad Biológica.Con esto, la Corte refuerza su argumento según el cual los animales no son titulares de derecho, aunque parecería ampliar el reconocimiento no sólo a la prohibición de maltrato, sino a la protección contra la extinción.

La Corte señala, derivado de los dos últimos instrumentos, la obligación de los Estados Partes a reconstruir las especies amenazadas y proteger las que están en vía de extinción. Así, establece nuevamente que de la Constitución y los instrumentos internacionales surgen obligaciones de cuidado y prohibiciones de maltrato y crueldad contra los animales, pero de ninguno de ellos se deduce un derecho fundamental del animal no humano. Empero, advierte sobre el deber de garantizar el mantenimiento y conservación de la biodiversidad y el control de procesos potencialmente peligrosos y adversos para el medio ambiente, sin que, por ello, la acción de tutela se convierta en el medio judicial para su protección.

En otras palabras, para la Corte, la acción de tutela como medio para la protección de los animales se ha dado en conexidad con los derechos fundamentales de los seres humanos, por ser éstos los únicos portadores de personalidad jurídica.

La Corte concluye en que las fuentes jurídicas disponibles son el deber constitucional de protección animal, el Estatuto de Bienestar Animal y la Ley 1774 de 2016. De esta manera, no existiría un medio idóneo, eficaz e inmediato para evitar el maltrato animal, pues la acción de tutela para la protección de bienestar animal es improcedente, dada la inexistencia de un derecho fundamental en cabeza de 
los animales, ni su exigibilidad por medio de la acción de tutela, al tratarse de un interés difuso, no individualizable. Esto supone entonces que los seres humanos deben evitar el maltrato, la tortura o los actos de crueldad y velar por el cuidado de su integridad y vida de los animales, cuyo medio de protección serán propios de las potestades policivas y punitivas de la ley 84 de 1989 y 1774 de 2016.

La sentencia C-045 de $2019^{56}$ se propone armonizar lo señalado previamente. En este fallo, la Corte decide la constitucionalidad de los artículos 248 (parcial), 252 (parcial) y 256 del Decreto 2811 de 1974, y, nuevamente, los artículos $8^{\circ}$ (parcial) y 30 (parcial) de la Ley 84 de 1989. El fallo intenta articular losámbitos de protección consignados en los precedentes citados y reconoce que el deber de protección animal es un límite al derecho de propiedad, pero a la vez encuentra como límites constitucionales admisibles a la protección de los seres sintientes: (i) la libertad religiosa; (ii) los hábitos alimenticios; (iii) la investigación y experimentación médica; y, en algunos casos, (iv) las manifestaciones culturales arraigadas.

Se trata de un fallo que definitivamente avanza en el reconocimiento jurídico de los animales como seres sintientes, en la medida en que censura el sacrificio abyecto y cruel de la vida de un ser vivo en el marco de la caza deportiva, entendiendo que dicho acto "es una forma extrema de maltrato en cuanto elimina su existencia misma y es un acto de aniquilamiento. Cuando es injustificada, la muerte de un animal es un acto de crueldad pues supone entender que el animal es exclusivamente un recurso disponible para el ser humano. La caza deportiva, en fin, es un acto dañino en cuanto está dirigida a la captura de animales silvestres, ya sea dándoles muerte, mutilándolos o atrapándolos vivos".

Con este argumento, la Corte es contundente y encuentra que la caza deportiva no halla fundamento en ninguna de las excepciones antes expuestas y reconocidas jurisprudencialmente, a la prohibición del maltrato animal. De esta manera, la Corte declaró la inconstitucionalidad de las normas accionadas relativas a la caza deportiva, pero, dado que algunas asociaciones demostraron que se trataba de una actividad económica que se amparaba en las normas demandadas con años de vigencia, decidió diferir los efectos de la decisión, por el lapso de un año, para que quienes resulten afectados con la determinación y así, protege su

56 Laura Juliana Santacoloma Mendez (2019), Acción Pública de Inconstitucionalidad, Sentencia C-045, Corte Constitucional. 
confianza legítima, sin que lo antedicho significara que las normas demandadas seguirían produciendo efectos.

La última sentencia que será comentada y hace parte de esta línea jurisprudencial es la SU-016 de 2020 $0^{57}$. Sus antecedentes son más complejos en la medida en que revocó un fallo de la Corte Suprema de Justicia sobre un recurso de habeas corpus que se interpuso a favor de un oso de anteojos (Tremarctos ornatus) llamado "Chucho". Este oso nació en la Reserva Natural La Planada, en el departamento de Nariño. A los cuatro años de edad fue trasladado a la Reserva Forestal Protectora del Río Blanco en Manizales, a cargo de Corpocaldas. Una vez la Fundación Botánica y Zoológica de Barranquilla (Fundazoo) manifestó su disposición de acoger un oso de anteojos, Corpocaldas le concedió la tenencia de Chucho, y esta se materializó el día 16 de junio de 2017. En esa fecha, el señor Luis Domingo Gómez Maldonado presentó habeas corpus en favor del oso, al considerar que su traslado al zoológico de Barranquilla daba lugar a un cautiverio permanente y en condiciones inapropiadas para su especie.

Esta acción fue resuelta desfavorablemente por la Sala Civil y de Familia del Tribunal Superior del Distrito Judicial de Manizales, sobre la base de que el habeas corpus no era el mecanismo adecuado para exigir la protección de los animales. Sin embargo, en segunda instancia, la Sala de Casación Civil de la Corte Suprema de Justicia revocó la decisión y concedió el recurso, ordenando a Fundazoo, a Corpocaldas, a Aguas de Manizales, a la Unidad Administrativa Especial del Sistema de Parques Nacionales Naturales y al Ministerio del Medio Ambiente acordar y disponer el traslado del oso "Chucho" a un lugar que se adecuara a sus necesidades, y en el que el oso pudiese permanecer en estado de semi-cautiverio.

A juicio de la Sala, aunque en principio el habeas corpus fue diseñado para garantizar la libertad de las personas, ello no excluye su utilización para exigir la protección de los animales como seres sintientes y como sujetos de derechos. El argumento central de la Corte fue el giro de la visión meramente antropocéntrica a una ecocéntrica-antrópica, en la cual el hombre es el responsable principal de la conservación del medio ambiente, en el marco de una "ciudadanía universal y biótica", que no puede ignorar "nuestra condición de seres vivos y anima-

57 Luis Domingo Gómez Maldonado Vs. Fundazoo, a Corpocaldas, a Aguas de Manizales, a la Unidad Administrativa Especial del Sistema de Parques Nacionales Naturales y al Ministerio del Medio Ambiente (2020) Acción de tutela, Sentencia SU-016, Corte Constitucional. 
les" 58 . Las entidades derrotadas en ese proceso presentaron acción de tutela, y ésta fue decidida en la Sala Laboral y la Sala Penal de la Corte Suprema de Justicia, concediendo la tutela y dejando sin efecto el habeas corpus. En otras palabras, este mecanismo dejó sin efectos la decisión que otorgaba el recurso para el oso "Chucho" y mantuvo las condiciones de cautiverio en el zoológico de la ciudad de Barranquilla.

Este asunto llegó a conocimiento de la Corte Constitucional, quien tenía en sus manos una ponencia que daba de una vez el paso al reconocimiento de la personalidad jurídica de los animales. En efecto, la Magistrada Diana Fajardo Rivera había presentado una ponencia en la que, a partir de cinco puntos, planteaba la necesidad de reconocer a los seres sintientes como titulares de derechos.

Para la Magistrada, los animales son titulares de intereses jurídicamente relevantes para nuestro ordenamiento, a la luz de la (i) la afirmación de los animales como seres sintientes con un valor intrínseco; (ii) los avances que contiene la Ley 1774 que reconoce la sintiencia e incorpora los mandatos de bienestar animal; (iii) las experiencias de derecho comparado, como los habeas corpus concedidos en Argentina a la orangutana "Sandra" y a la chimpancé "Cecilia"; (iv) el compromiso humano con la conservación del medio ambiente, que se expresa en varios instrumentos internacionales como la Convención sobre el Comercio Internacional de Especies Amenazadas de Fauna y Flora Silvestres -CITES-; y, (v) las aportaciones teóricas, filosóficas y científicas que dan cuenta, por un lado, de que las categorías jurídicas deben permitir comprender y dar respuesta a verdaderos problemas constitucionales, como el trato que debemos a los animales; $y$, por el otro, de la riqueza que se encuentra en otras especies, de sus propias experiencias de vida e, incluso, de las semejanzas que respecto de algunas de las capacidades humanas exhiben varios animales.

Con todo, en la ponencia, la magistrada hizo hincapié en que el reconocimiento de la titularidad de derechos no hacía a los animales equivalentes al hombre ni

58 Luís Domingo Gómez Vs. Fundación Botánica y Zoológica de Barranquilla, la Corporación Autónoma Regional de Caldas, Aguas de Manizales S.A. ESP-, la Unidad Administrativa Especial del Sistema de Parques Nacionales Naturales y el Ministerio de Ambiente y Desarrollo Sostenible (2017), Corte Suprema de Justicia - Sala de Casación Civil y Agraria. La Corteordenó a la, acordar y disponer en un término no mayor a 30 días contados a partir de la ejecutoria de la presente providencia, el inmediato traslado del oso de anteojos, andino, o tremarctos ornatus de nombre "Chucho", confinado actualmente en el zoológico de Barranquilla, a una zona que mejor se adecué a su hábitat, con plenas y dignas condiciones de semicautiverio, conforme lo exige la normatividad respectiva, teniendo como destino prioritario la Reserva Natural Río Blanco, lugar que ha sido su casa durante 18 años. 
pretendía ordenar la libertad del oso para llevarlo a un ambiente donde no pueda sobrevivir sin el acompañamiento humano. La ponencia se dirigía a desenredar el "laberinto formalista" y procesal que deja sin herramientas eficaces de protección a los animales, pero no intentaba ordenar la libertad física del oso.

No obstante, la posición mayoritaria de la Corte confirmó las decisiones de instancia, para ratificar entonces que el habeas corpus -al igual que la acción de tutela- no son mecanismos constitucionales que estén diseñados para la protección de los animales. La Corte reitera lo dicho en fallos anteriores en el sentido de reconocer el maltrato como un hecho con consecuencias jurídicas que cuenta con herramientas específicamente orientadas a hacer efectivos esos mandatos, que pueden ser perfeccionadas, para brindar mayor efectiva "frente a acciones u omisiones que resulten contrarias a esos imperativos que se derivande la Constitución $y$, en particular, en aquellos que permitan canalizar los debatesrelacionados con el confinamiento y el cautiverio de animales silvestres por instanciasautorizadas por el Estado, según los estándares del bienestar animal”.

La ponencia de la magistrada Diana Fajardo estuvo acompañada por el magistrado Alberto Rojas, quien, al ser vencido, salvó su voto y quizá, fue más allá al enunciar una lista de derechos y utilizar la categoría de animal no humano. Para el magistrado, esta condición implica reconocer en ellos los derechos a (i) no tener hambre, sed, ni malnutrición; (ii) no tener miedo ni angustia; (iii) no padecer molestias físicas; (iv) no ser sometido a daños, lesiones o enfermedades; (v) libertad para expresar sus patrones naturales de comportamiento, puede tener una categoría jurídica de persona, que tiene sustrato en que se trata de seres sintientes y que se encuentran en un punto intermedio entre sujetos y objetos del derecho. Inclusive, señala el salvamento de voto del magistrado Rojas, el debate y la decisión mayoritaria de la Corte dejó de lado una verdadera discusión que permitiera trascender "el antropocentrismo para llegar finalmente al biocentrismo".

La línea jurisprudencial descrita da cuenta entonces de dos fuentes y a la vez límites al amparo y reconocimiento de la personalidad jurídica de los seres sintientes. En primer lugar, extrae de la defensa constitucional del medio ambiente y de prohibiciones legales, la protección de crueldad y el reconocimiento de una condición jurídica intermedia entre objetos y sujetos a través de la categoría de seres sintientes, aproximándose, aunque no definitivamente, a la protección inclusive de la extinción por mano del hombre. 
Sin embargo, de allí el límite, la línea jurisprudencial no reconoce finalmente la personalidad jurídica de los animales e impide la procedibilidad de mecanismos constitucionales expeditos -como la tutela o el habeas corpus-, imbuyendo el debate en el "laberinto formalista" antes descrito, atando la protección animal a la conexidad con derechos fundamentales de los seres humanos o vinculándolo directamente con la protección constitucional al ambiente sano y la diversidad de la flora y la fauna. Lo antedicho supone entonces un avance limitado a la protección constitucional y un avance más formal, donde las Cortes han sido cuidadosas en evitar el reconocimiento de derechos de los animales.Al final de cuentas, la categoría intermedia de ser sintiente no parecería profundizar mucho más lo dispuesto en el estatuto de protección animal de 1989.

Lo anterior cambia con la personalización jurídica de la naturaleza, pues en este caso, no se reconoce la sintiencia ni la sensibilidad de los ecosistemas, pero la protección constitucional es más intensa. Como se procederá a demostrar, la razón de ser del reconocimiento de la naturaleza como sujeto de derecho proviene de la dependencia de individuos de los recursos naturales que se encuentran allí. Se trata de derechos bioculturales y de la equidad intergeneracional, que justifica una intervención judicial más fuerte, pero que de alguna manera, continua siendo antropocentrista.

\section{La personalidad jurídica de ecosistemas, las sentencias estructurales de segunda generación como medio para garantizar los derechos de generaciones futuras}

Como se mencionó, Nueva Zelanda fue el primer país en reconocer derechos a un río (río Whanganui), y junto a Ecuador (está en su Constitución), Bolivia (Ley de la Madre Tierra) e India (Rios Ganges y Yamuna), Colombia ha reconocidopersonalidad jurídica a varios ecosistemas. Con todo, como se procederá a demostrar, esta línea que parecería vinculada a la anterior, permite evidenciar la diferencia entre la posición ecocentrica y biocéntrica, pues en la primera se reconocerían los derechos de la naturaleza mientras que en la segunda de los seres sintientes. Como se procederá a argumentar, estas posiciones son finalmente correlativas a la posibilidad de demostrar un vínculo entre los derechos fundamentales de los seres humanos y los seres sintientes o los ecosistemas protegidos.

En otras palabras, las Cortes sólo adoptan una posición aparentemente ecocéntrica o biocéntrica si la protección de la naturaleza o los ecosistemas brindan 
eficacia a los derechos fundamentales de las personas. En otras palabras, parecería tratarse de una segunda generación de sentencias estructurales que identifican una violación masiva y sistemática de derechos fundamentales de las personas, nacidas y por nacer, pero cuya eficacia se encuentra condicionada a la protección del ecosistema que será protegido. En efecto, como se expondrá en el presente trabajo, el activismo judicial juega un importante rol en la extensión de sujetos de derechos y de protección. No obstante, parecerían reconocer el mutualismo y la dependencia que el ser humano tiene con el planeta, pero cuenta con restricciones internas para limitar actividades económicas intensivas y nocivas para el ambiente y la fauna.

Ahora bien, a diferencia del reconocimiento de los animales como seres sintientes, como se mencionó previamente, la personalización jurídica de los derechos de la naturaleza no se construye a partir del reconocimiento de sustratos neurológicos de dichos ecosistemas. Al contrario, se reconoce personalidad jurídica a ecosistemas con el propósito de brindar eficacia a los derechos fundamentales de quienes dependen de ellos y del principio de equidad intergenaracional.

En Colombia, río Atrato, páramo de Pisba, la Amazonía, el río Cauca, río Magdalena, río Quindío, Parque Nacional Natural los Nevados y el Parque Vía Isla Salamanca, han sido reconocidos como sujetos de derecho. Todos ellos, amenazados por actividades antrópicas intensivas, que, a la vez, podrían poner en riesgo los derechos de los individuos. Dos aspectos son llamativos de estas sentencias: primero, se trata de ecosistemas amenazados por monocultivos, cultivos ilícitos, ganadería intensiva, explotación de minería legal e ilegal y deforestación; segundo, los derechos fundamentales que se están defendiendo son los de las generaciones presentes y futuras, en una suerte de solidaridad intergeneracional.

\subsection{La solidaridad intergeneracional como eje jurisprudencial para la personalización jurídica de ecosistemas}

La Sentencia T-622 de 2016 es probablemente el fallo hito, en tanto contiene una serie de valores y una exposición amplia de razones de ser de la decisión, y se convierte en el eje de las sentencias que sobrevinieron al decidir sobre asuntos análogos. Para esta sentencia, los ejes normativos que desplazan la personalidad jurídica de los individuos al ecosistema yacen en los derechos de las comunidades 
étnicas $-\mathrm{y}$ sus derechos bioculturales-59 que dependen de dicho río, el derecho al medio ambiente -principios de precaución y prevención- y el derecho al agua potable y seguridad alimentaria.

En este fallo, la Corte Constitucional constata que la situación afecta a un número significativo de personas, que ésta es consecuencia de la prolongada omisión de las autoridades en el cumplimiento de sus obligaciones para garantizar los derechos ${ }^{60}$, exige la expedición de medidas legislativas, administrativas o presupuestales necesarias para evitar la vulneración de los derechos y su solución compromete la intervención de varias entidades, que demanda un esfuerzo presupuestal adicional importante.

En otras palabras, es notable que se trata de un juicio de estado de cosas inconstitucional y de un remedio judicial estructural (Osuna, 2015), producto del uso intensivo y a gran escala de diversos métodos de extracción minera y de explotación forestal ilegales, que incluyen maquinaria pesada -dragas y retroexcavadoras- y sustancias altamente tóxicas -como el mercurio- en el río Atrato (Chocó). La Corte encuentra probado que la mayoría de actores que ejercen la minería en ese territorio carece títulos mineros y de licencias ambientales necesarias. Inclusive, gran parte de la actividad minera ocurre en zonas de reserva forestal -anota la Corte- donde precisamente estas actividades están prohibidas. Estas actividades afectan el río Atrato, el río Quito, el río Andágueda (territorio de Cocomopoca), el río Bebará y el río Bebaramá (territorio de Cocomacia). La fuente más nociva de contaminación yace en los vertimientos de mercurio y otras sustancias e insumos, además de la dispersión de vapores en los entables mineros.

59 Los derechos bioculturales representan la unión entre ambiente y cultura desde una perspectiva holística, identificado con la idea de arraigos culturales propios de ciertos ecosistemas. nace como un concepto que visibiliza la interpenetración entre los pueblos indígenas y/o campesinos y los recursos naturales, los ecosistemas y los territorios donde se han asentado a través de los siglos. Esponda y KeINRAD (2017), p. 58.

6o En este proceso fueron demandados el Departamento Administrativo de la Presidencia de la República, Ministerio de Interior, Ministerio de Ambiente y Desarrollo Sostenible, Ministerio de Minas y Energía, Ministerio de Defensa Nacional, Ministerio de Salud y Protección Social, Ministerio de Agricultura, Ministerio de Vivienda, Ciudad y Territorio, Ministerio de Educación, Departamento para la Prosperidad Social, Departamento Nacional de Planeación, Agencia Nacional de Minería, Agencia Nacional de Licencias Ambientales, Instituto Nacional de Salud, Departamentos de Chocó y Antioquia, Corporación Autónoma Regional para el Desarrollo Sostenible del Chocó -Codechocó-, Corporación para el Desarrollo Sostenible del Urabá -Corpourabá-, Policía Nacional - Unidad contra la Minería Ilegal, Instituto Geográfico Agustín Codazzi -IGAC-, Instituto Colombiano de Desarrollo Rural -Incoder-, Registraduría Nacional del Estado Civil, Defensoría del Pueblo, Contraloría General de la República, Procuraduría General de la Nación, Municipios de Acandí, Bojayá, Lloró, Medio Atrato, Riosucio, Quibdó, Río Quito, Unguía, Carmen del Darién, Bagadó, Carmen de Atrato y Yuto (Chocó), y Murindó, Vigía del Fuerte y Turbo (Antioquia). 
En este fallo, la Corte Constitucional toma la decisión de declarar sujeto de derecho a un ecosistema con un argumento claramente mutualista. La Corte toma como marco normativo de referencia la "constitución ecológica", de donde resalta la relación "transversal" del ordenamiento constitucional con la naturaleza y el medio ambiente. Sin embargo, esta protección gana relevancia en la medida en que los seres humanos dependen de un ambiente sano para llevar "una vida digna y en condiciones de bienestar", pero también en relación a los demás organismos vivos con quienes se comparte el planeta, entendidas como existencias merecedoras de protección en sí mismas.

La Corte resalta "[s]e trata de ser conscientes de la interdependencia que nos conecta a todos los seres vivos de la tierra; esto es, reconocernos como partes integrantes del ecosistema global -biósfera-, antes que, a partir de categorías normativas de dominación, simple explotación o utilidad". Junto a esta reflexión, la Corte resalta en el caso concreto, el concepto de derechos bioculturales, en tanto las comunidades indígenas, étnicas, tribales y tradicionales, ubicadas en el territorio, "tienen fuertes vínculos culturales y espirituales, con sus tierras tradicionales y sus recursos".

En otras palabras, la Corte parecería transmitir los atributos de los derechos bioculturales al ecosistema mismo, brindándole personalidad jurídica como medio para garantizar su eficacia, dada la falla estructural y sistemática que lo amenaza. Con ello, se brinda eficacia a los derechos bioculturales a todos los individuos que dependen del río Atrato.

El mismo nicho citacional construido por la Corte Constitucional en la sentencia comentada, permite constatar cómo evolucionó la protección al medio ambiente, como derecho colectivo cuya eficacia por vía de tutela dependía de una conexidad probada con un derecho fundamental, a un amparo al derecho a la existencia del ecosistema, en tanto existe una conexidad subyacente y presunta entre la existencia del ecosistema y la de las comunidades ancestrales y étnicas que dependen de él. Lo antedicho, reforzado para este caso y tratándose de una fuente hídrica, por el derecho al agua, cada vez más relevante en instrumentos internacionales y diversas resoluciones de las Naciones Unidas, reconocidos por la Corte Constitucional.

No obstante, la sentencia T-622 de 2016 no se convirtió de inmediato en una subregla. Ejemplo de esto es la sentencia T-596 de 2017, donde se presentó una acción de tutela por parte de los pescadores tribales de la Ciénaga Grande de Santa 
Marta, ecosistema que se encuentra en una notable crisis ambiental ocasionada por la omisión continua y permanente de las entidades accionadas y ha comprometido los derechos fundamentales de miles de personas. La continua privación de agua dulce a la CGSM, la acumulación de materia orgánica en descomposición y el aumento de la temperatura dada la pérdida de profundidad de la Ciénaga, habían provocado en el 2014, cuando menos, 5 mortandades masivas de peces y animales silvestres.

En julio y septiembre de 2015, y en la última semana de julio y en la segunda semana de agosto de 2016, se presentaron de igual manera, mortandades masivas, siendo esta última, la más notable y dramática. Estos hechosdaban cuenta de la vulneración masiva, estructural y sistemática de los derechos fundamentales de los habitantes del sistema estuarino de la Ciénaga Grande de Santa Marta.Sin embargo, el Tribunal Superior de Distrito Judicial del Magdalena, la Corte Suprema de Justicia-Sala Civil y la Corte Constitucional, negaron en cada instancia la procedibilidad de la acción de tutela, pues consideraron que el derecho que se está vulnerando es el derecho al medio ambiente y saneamiento básico, desconociendo los derechos fundamentales antes mencionados y lo más importante, la existencia del ecosistema como un medio para garantizar los derechos bioculturales de las poblaciones que dependían de ese ecosistema.

En la sentencia T-596 de 2017 la Corte retrocede al "laberinto formalista" y considera que la acción de tutela no era el medio idóneo para garantizar los intereses colectivos a pesar de la intersección probada entre la existencia de comunidades pesqueras portadoras de una cosmovisión y singularidad cultural, particularmente arraigadas al cuerpo lagunar, y la salud y existencia del ecosistema ${ }^{61}$.

En el proceso se daba cuenta, entre otras cosas, de la ineficacia instrumental del Estado y la ausencia de un modelo hidrológico que refleje las dinámicas actuales de la Ciénaga Grande de Santa Marta y de un instrumento que permita garantizar que tanto en épocas de sequía como en épocas de lluvia haya un flujo

61 Estas poblaciones son comunidades palafiticas asentadas sobre la Ciénaga Grande de Santa Marta. Las condiciones favorables de la ecorregión CGSM, tales como la presencia de agua dulce y la pesca abundante de especies marinas y fluviales, dieron origen a una ocupación lenta, pero muy antigua, que se dio paulatinamente. Primero, se establecieron campamentos temporales de pescadores, que posteriormente se convirtió en una población permanente que construyó sus viviendas sobre estacas clavadas en el fondo de las ciénagas, que sobresalían por encima del nivel del agua, a las cuales les colocaban un cobertizo que llegaba hasta el nivel del agua de manera que el techo les servía de pared. Fue así como se formaron los actuales pueblos de palafitos de Nueva Venecia (antes llamado El Morro), Buenavista y Bocas de Aracataca (o Trojas de Cataca). El más antiguo es Nueva Venecia que se originó en 1847.SARMiento (2019b), p. 63. 
suficiente de agua dulce hacia el complejo lagunar. También se daba cuenta de la desviación, contaminación y sedimentación de las fuentes de agua dulce por parte de cultivadores de palma africana, banano, arroz y otras actividades agrícolas y ganaderas intensivas. En el proceso inclusive se pretendía garantizar el acceso al agua y reparar las consecuencias que tiene para la salud y los riesgos a la vida, principalmente de los niños, niñas y adolescentes, como consecuencia de las enfermedades respiratorias, virales y diarreicas dada la situación ambiental de este ecosistema estratégico para el Caribe.

La anterior parece ser una desafortunada excepción, pues el caso de la Amazonía retoma y reitera lo señalado en la Sentencia T-622 de 2016, con un espectro de destinatarios de protección mucho más amplio. Sin embargo, esta decisión es tomada por la Corte Suprema de Justicia y resuelve una tutela presentada por un grupo de 25 niños, niñas, adolescentes y jóvenes adultos, entre 7 y 25 años de edad, que viven en ciudades que hacen parte de la lista de ciudades de mayor riesgo por cambio climático. Esta acción es novedosa en tanto quienes presentan la acción, reclaman su derecho a la vida, prospectivamente. En la demanda se resaltan algunas causas que amenazan la Amazonía, entre ellos, el acaparamiento de tierras (6o-65\%), los cultivos de uso ilícito (20-22\%), la extracción ilícita de yacimientos minerales (7-8\%), la infraestructura, los cultivos agroindustriales y la extracción ilegal de madera.

Con todo, como se insinuó previamente, se trata de una sentencia estructural de "segunda generación". Ciertamente, la Corte Suprema encuentra una violación sistemática y masiva de derechos, pero en lugar de declarar un estado de cosas inconstitucional, opta por declarar la personalidad jurídica de un ecosistema, constatando nuevamente que la situación afecta a un número significativo de personas, como consecuencia de la prolongada omisión de las autoridades en el cumplimiento de sus obligaciones para garantizar los derechos ${ }^{62}$, exige la expedición de medidas legislativas, administrativas o presupuestales necesarias para evitar la vulneración de los derechos y su solución compromete la intervención de varias entidades, que demanda un esfuerzo presupuestal adicional importante.

$62 \mathrm{Al}$ proceso fueron accionados el Departamento Administrativo de la Presidencia de la República, el Ministerio de Agricultura y Desarrollo Rural, el Ministerio de Ambiente y Desarrollo Sostenible, la Contraloría Delegada para el Medio Ambiente, la Procuraduría Delegada para Asuntos Ambientales, Parques Nacionales Naturales de Colombia, la Gobernación de Putumayo, el Departamento de Guaviare, y la Gobernación de Caquetá, el Municipio de San Vicente del Caguán, la Alcaldía de Solano, Corpoamazonía, entre otros. 
En la citada sentencia, la Corte Suprema hace un diagnóstico de los riesgos que supone el agotamiento de los recursos naturales y de ecosistemas, así como sus causas. Así, la Corte advierte que los riesgos del "antropoceno"63 se resumen en la ascendente dificultad para obtener los medios indispensables de subsistencia para la población mundial y la contaminación y mutación de nuestro entorno por la colonización irracional de bosques y ampliación de las fronteras urbanas, agrícolas, industriales y extractivas que aumentan la deforestación.

Esto ocurre, expone la Corte, por la adopción de un "modelo antropocéntrico y egoísta, cuyos rasgos característicos son nocivos para la estabilidad ambiental, a saber: i) el desmedido crecimiento demográfico; ii) la adopción de un vertiginoso sistema de desarrollo guiado por el consumismo y los sistemas político- económicos vigentes; y iii) la explotación desmedida de los recursos naturales".Continúa la Corte en su exposición de las relaciones biológicas obvias que tenemos con nuestro entorno y el vínculo entre el interés general y las actividades antrópicas, que incumben a los individuos de ahora y "los sujetos aun no nacidos, quienes merecen disfrutar de las mismas condiciones medioambientales vividas por nosotros". Esta solidaridad -equidad- intergeneracional se ampara, opina la Corte, en el "(i) deber ético de la solidaridad de la especie y (ii) en el valor intrínseco de la naturaleza" 64 .

Para la Corte Suprema, es un precedente relevante la Sentencia T-622 de 2016 de la Corte Constitucional, en tanto reconoce la personalidad jurídica del ecosistema, "no por la simple utilidad material, genética o productiva que estos puedan representar para el ser humano", sino porque, cita la Corte Suprema de la Corte Constitucional, "al tratarse de una entidad viviente compuesta por otras múltiples formas de vida y representaciones culturales, son sujetos de derechos individualizables, lo que los convierte en un nuevo imperativo de protección integral y respeto por parte de los Estados y las sociedades". En efecto, la Corte Suprema

$63 \mathrm{El}$ antropoceno es descrita como una nueva época geológica como consecuencia de la magnitud de la transformación de los procesos naturales a escala global resultado de las actividades de los seres humanos, a causa del uso de los combustibles fósiles y del incremento considerable de óxido nitroso, dióxido de carbono, metano y denuevos gases como los cloro-fluoro-carbonos en la atmósfera y que pueden atentar contra la propia existencia de la humanidad. ZAmora et al (2016), p. 67.

64 Andrea Lozano Barragán, Victoria Alexandra Arenas Sánchez, José Daniel y Félix Jeffry Rodríguez Peña, entre otros, Vs. Presidencia de la República, los Ministerios de Ambiente y Desarrollo Sostenible y de Agricultura y Desarrollo Rural, la Unidad Administrativa Especial de Parques Nacionales Naturales y las Gobernaciones de Amazonas, Caquetá, Guainía, Guaviare, Putumayo y Vaupés (2018), Corte Suprema de Justicia, Sala de Casación Civil. 
construye su argumento desde la misma narrativa de la sentencia de la Corte Constitucional relativa al río Atrato y se ampara en una conexidad entre el ecosistema, la protección a la singularidad y el pluralismo cultural y la dependencia humana -biológica- de su entorno.

En el marco de este caso, la Corte Suprema emite una sentencia estructural, donde ordena, con plazos precisos, y quizá demasiado cortos, a múltiples entidades a tomar medidas para reducir la deforestación en la Amazonía. Así, se ordenó a la Presidencia de la República, al Ministerio de Ambiente y Desarrollo Sostenible, y a la Cartera de Agricultura y Desarrollo Rural para que, en coordinación con los sectores del Sistema Nacional Ambiental, y la participación de los accionantes, las comunidades afectadas y la población interesada en general, dentro de los 4 meses siguientes a la notificación del fallo, formulen un plan de acción de corto, mediano y largo plazo, que contrarreste la tasa de deforestación en la Amazonía, en donde se haga frente a los efectos del cambio climático.

También ordenó a la Presidencia de la República, al Ministerio de Ambiente y Desarrollo Sostenible, y al Ministerio de Agricultura y Desarrollo Rural, formular -en 5 meses- un "pacto intergeneracional por la vida del amazonas colombiano -PIVAC"; a los municipios de la Amazonía -en 5 meses- se les impuso la obligación de actualizar e implementar en los Planes de Ordenamiento Territorial, planes de acción de reducción cero de la deforestación en su territorio; a la Corporación para el Desarrollo Sostenible del Sur de la Amazonía -Corpoamazonia, la Corporación para el Desarrollo Sostenible del Norte y el Oriente Amazónico CDA, y la Corporación para el Desarrollo Sostenible del Área de Manejo Especial La Macarena -Cormacarena, - en 5 meses-, se les ordenó diseñar e implementar un plan de acción que contrarreste mediante medidas policivas, judiciales o administrativas, los problemas de deforestación informados por el IDEAM.

El fallo inclusive ordenó que en 48 horas desde que se notificó la sentencia, incrementaran las acciones tendientes a mitigar la deforestación mientras se llevan a cabo las otras acciones. Como se constata, de las órdenes emitidas previamente, se puede dar cuenta de la referencia a una segunda generación de sentencias estructurales, donde se advierte la prolongada omisión de las autoridades en el cumplimiento de sus obligaciones para garantizar los derechos, se exige la expedición de medidas administrativas o presupuestales necesarias para evitar la vulneración de los derechos y su solución compromete la intervención de varias entidades, cuya omisión provocó la situación inconstitucional. 


\subsection{La cascada de precedentes uniformes de cara a la protección de los derechos de generaciones futuras}

Los anteriores precedentes provocaron una cascada de sentencias que reconocieron a otros dos ecosistemas como sujetos de derecho, esta vez en manos de Tribunales. En efecto, se trató del río Cauca y el páramo de Pisba, brindándole personalidad jurídica por el Tribunal Superior de Medellín -Sala Cuarta Civil de Decisión- Tribunal Administrativo de Boyacá-Sala de Decisión-, respectivamente.

El páramo de Pisba fue reconocido como sujeto de derecho por medio de una acción de tutela interpuesta por más de 70 individuos que buscaban el amparo de su derecho al trabajo, en la medida en que laboraban en la Empresa CI Bulk Trading Sur América Ltda., titular y operadora de un Contrato de Concesión Minera en territorio del páramo ${ }^{65}$. Recogiendo los argumentos y razones de la decisión T-622 de 2016 de la Corte Constitucional y de la Sentencia STC4360-2018 de la Corte Suprema de Justicia, el Tribunal identifica la posición ecocéntrica y, desde un enfoque también mutualista, señala que "los deberes enunciados como a cargo del Estado, no pueden ser satisfechos si previamente no se da a los páramos la especial protección que merecen como sujetos de derechos, y como entes de los cuales también se derivan ciertos derechos fundamentales y colectivos de la población que de éste dependen".

Con todo, el Tribunal Administrativo se encuentra en un caso más complejo, en la medida en que se debió hacer una ponderación entre los derechos del páramo a "su conservación e integridad como ecosistema", el derecho fundamental al agua de las comunidades beneficiarias del páramo, los derechos a la vida, a la salud, a la integridad personal de dichos individuos, y los derechos al trabajo, a la libertad para escoger profesión u oficio y al libre desarrollo de la personalidad de las comunidades que extraían minerales del páramo. Aunque el Tribunal identifica la necesidad de hacer prevalecer los derechos del páramo, identifica la necesidad de reconocer el derecho a la participación de los pobladores de esa zona, en el marco de la sentencia T-361 de 2017 de la Corte Constitucional, que versaba también sobre la protección de otro páramo (Santurbán), pero donde el debate se centró en la participación ciudadana en la delimitación del páramo y su conservación.

65 Juan Carlos Alvarado Rodríguez y otros, Vs. Ministerio de Medio Ambiente y otros; Tribunal Administrativo de Boyacá. 
El fallo del Tribunal Administrativo declaró explícitamente al Páramo de Pisba como sujeto de derechos y explícitamente señaló los alcances de esta decisión en los siguientes términos: "Se le aplicará el Convenio de Diversidad Biológica; Se le concede estatus de protección auto ejecutiva; El Ministerio de Ambiente y Desarrollo Sostenible tiene el deber de delimitar las áreas del Páramo de Pisba bajo criterios eminentemente científicos; El Ministerio de Ambiente y Desarrollo Sostenible, o quien el presidente de la Republica designe, actuará como representante legal del Páramo de Pisba; El Ministerio de Ambiente y Desarrollo Sostenible, deberá actuar como representante del Páramo de Pisba ante la Agencia Nacional de Minería; Las Corporaciones Autónomas Regionales de la Orinoquia y de Boyacá, no podrán autorizar nuevos planes de manejo ambiental que tengan por objeto servir de requisito a la obtención de un título minero en las zonas que sean delimitadas como páramo de Pisba.

Luego del anterior caso, se resolvió una acción de tutela para la protección del río Cauca en el marco de la construcción de una hidroeléctrica, llamada Hidroituango ${ }^{66}$. En el marco de una sentencia estructural, se accionaron a múltiples entidades por acciones y omisiones ${ }^{67}$ que amenazaban el caudal del río, así como su diversidad y los derechos de los habitantes que dependían de él. Aunque el proyecto fue polémico desde el inicio de la obra, el 6 de febrero de 2019 se materializó la crisis en razón de problemas técnicos que llevaron a cerrar la compuerta 1 de la casa de máquinasde la represa, y como consecuencia, disminuyódrásticamente el caudal del río, impactando el ecosistema de fauna yflora y las actividades antrópicas que dependían del recurso hídrico.

Aunque el Tribunal Superior de Medellín toma como precedente vinculante la sentencia T-622 de 2016 de la Corte Constitucional, hace una amplia discusión nuevamente sobre la procedibilidad de la acción de tutela para la protección de

66 Juan Luis Castro Córdoba y Diego Hernán David Ochoa Vs. Ministerio de Ambiente y Desarrollo Sostenible, EPM, Hidroeléctrica Ituango S.A. E.S.P. y otros (2019), Tribunal Superior de Distrito Judicial de Medellín, Sala Cuarta Civil De Decisión.

67 En este proceso fueron convocados EPM E.S.P, Gobernación de Antioquia, Ministerio de Ambiente y Desarrollo Sostenible, Agencia Nacional de Licencias Ambientales- ANLA, Corantioquia y las vinculadas Hidroeléctrica Ituango S.A. E.S.P., Presidencia de la República de Colombia, Gobernación de Córdoba, Gobernación de Sucre, Gobernación de Bolívar, Corporación Autónoma Regional de los Valles del Sinú y del San Jorge - CVS-, Corporación Autónoma Regional de Sucre-CARSUCRE- Corporación Autónoma Regional del Sur de Bolívar-CSB-, Municipio de Ituango, Municipio de Valdivia, Municipio de Tarazá, Municipio de Cáceres, Municipio de Caucasia, y Municipio de Nechí en el departamento de Antioquia, Municipio de Guaranda en el Departamento de Sucre, Municipio de San Jacinto del Cauca, Municipio de Achí, y Municipio de Magangué en el departamento de Bolívar, y la Corporación para el Desarrollo Sostenible de la Mojana. 
derechos colectivos como el ambiente sano. Con todo, al igual que la sentencia de la Corte Constitucional y la Corte Suprema de Justicia, el Tribunal Superior toma como punto de partida la ponderación entre la transformación territorial con fines productivos, la utilización de los recursos naturales y humanos para el logro de condiciones de vida dignas para la población actual y las condiciones de existencia y supervivencia de las generaciones futuras.

Es relevante señalar que, al igual que las anteriores sentencias citadas, el Tribunal construye un bloque de constitucionalidad con instrumentos de derecho internacional que no parecerían orientarse necesariamente a la protección de Derechos Humanos -en el marco del artículo 93 de la Constitución-, sino que amplía el espectro de eficacia de tratados sobre la protección al medio ambiente y la biodiversidad, como un medio para garantizar los derechos a la existencia de las generaciones futuras. Con esto, el Tribunal, tomando los precedentes citados aquí, así como tratados y pactos internacionales -curiosamente no son novedosos y algunos datan de 1997-, resuelve cómo adjudicar derechos fundamentales a las generaciones futuras, para que sin tener existencia aún, gocen desde ya de aquellos derechos.

Así, el Tribunal concluye “(i) Que las generaciones futuras son sujetos de derechos de especialísima protección, (ii) que tienen derechos fundamentales a la dignidad, al agua, a la seguridad alimentaria y al medio ambiente sano, y (iii) que el río Cauca es sujeto de derecho, que implica, al igual que se hizo con el río Atrato, su protección, conservación, mantenimiento y restauración, a cargo del Ente Público Municipal y del Estado", ordenando al Gobierno Nacional ejercer la tutoría y representación legal de los derechos del río, a través de la Institución que el Presidente designe.

El caso más reciente fallo que parecería haber consolidado esta línea jurisprudencial es del 18 de junio de $2020^{68}$. En este proceso, la Corte Suprema de Justicia declaró como sujeto de derecho a la Vía Parque Isla de Salamanca, y ordenó formular un plan estratégico y efectivo de acción a cinco meses para reducir sus niveles de deforestación y degradación a cero (o). La declaratoria se produce luego de que el Grupo de Litigio e Interés Público de la Universidad del Norte

68 Luís Miguel Llorente (Grupo de Litigio de Interés Público de la Universidad del Norte Vs. Ministerio de Ambiente y Desarrollo Sostenible (MADS), a la Unidad Administrativa Especial de Parques Nacionales Naturales, a la Procuraduría General de la Nación, a la Fiscalía General de la Nación, a la Policía Nacional de Colombia y otros (2020), Corte Suprema de Justicia, Sala de Casación Civil. 
presentara el 21 de febrero de 2019 una acción de tutela que buscaba garantizar el derecho a la salud y la vida digna de niños y niñas de Barranquilla, amenazados como consecuencia de las quemas indiscriminadas que se presentan desde hace más de una década en el parque nacional natural.

Este parque además, contaba con varias declaratorias de protección, como por ejemplo, la Convención Ramsar, Reservas de la Biosfera por la UNESCO; área de importancia internacional para la conservación de aves -IBA/AICA- dentro de la iniciativa de Birdlife International y la Unión Internacional para la Conservación de la Naturaleza -UICN-, y es un área natural pertenecientes al Sistema de Parques Nacionales Naturales de Colombia.

En el proceso fueron vinculados el Ministerio de Ambiente y Desarrollo Sostenible (MADS), a la Unidad Administrativa Especial de Parques Nacionales Naturales, a la Procuraduría General de la Nación, a la Fiscalía General de la Nación, a la Policía Nacional de Colombia, a la Corporación Autónoma Regional del Magdalena (CORPAMAG), a la Corporación Autónoma Regional del Atlántico (CRA), al Distrito de Barranquilla y su autoridad ambiental "Barranquilla Verde" y al Departamento del Magdalena. "Dicha planeación deberá contener compromisos, autoridades responsables, ejes de acción y fechas concretas para la promoción de actuaciones de prevención y restauración del VPIS, así como las consecuencias en caso de incumplimiento, de acuerdo con las disposiciones legales en materia ambiental" señala la sentencia.

De igual forma, el fallo estableció el plazo de 2 meses para que las autoridades vencidas en el proceso conformen un Comité Permanente de Seguimiento al plan estratégico, cuyos integrantes deben enviar informes bimensuales a la Corte y al Tribunal de primera instancia por el término inicial de 2 años. La Corte Suprema fue enfática en criticar a las entidades accionadas y señaló que "las oficinas querelladas no han desplegados las acciones pertinentes y oportunas para corregir el impacto de las quemas indiscriminadas que se han dado".

Quizá, dos aportes son esenciales para este fallo y por ello, se afirma que puede consolidar la línea jurisprudencial. Primero, porque reconoce al ecosistema como un organismo vivo "dado que el medio ambiente y toda forma de vida que lo compone está dotado de por sí y ante sí, de ciertas prerrogativas autónomas. Esto quiere decir que tiene derechos, y que se espera que el accionar de las instituciones a partir de la declaratoria, salvaguarde la vida de su ecosistema. 
De esta forma, comprende al hombre, la flora y la fauna, "comparten la $p a-$ cha mama en un plano igualitario e interdependentista, en el que se cohesionan para hacer llevadera la vida de todos en La Tierra, de donde se sigue que deben propender armónicamente por evitar la degradación del medio ambiente, la contaminación del aire, la extinción de especies animales, la sequía de las cuencas hídricas, las enfermedades colectivas (pandemias) y todo el impacto negativo que produce el uso desmedido, descontrolado, abusivo e inadecuado de los denominados recursos naturales". Es así, como la Corte da un paso más en una dimensión de igualdad de la existencia del ecosistema, con la existencia humana.

El segundo aporte que consolida la línea consiste en ampliar y reconocer el bloque de constitucionalidad de tratados internacionales, entre los que se enunciaron al inicio de este documento, y con ello, se eleva la protección al medio ambiente, al asimilarlo a un derecho humano. Entre los tratados internacionales que "constitucionaliza" el fallo se encuentran la Declaración de Estocolmo para la Preservación y Mejoramiento del Medio Ambiente Humano de 1972, la Carta Mundial de la Naturaleza de las Naciones Unidas de 1982,la Convención Marco de las Naciones Unidas para el cambio climático de 1994, el Acuerdo de París de 2015, el Convenio sobre Diversidad Biológica de Río de Janeiro de 1992, el Convenio de Estocolmo, suscrito por Colombia en 2001. Con estos tratados internacionales, la Corte Suprema de Justica amplía el espectro e integra a la "'unidad jurídica de especial jerarquía constitucional".

Inclusive, la Corte va más allá e invoca al Sistema Interamericano de Protección de los Derechos Humanos, entre los que se cuenta la Convención Americana de Derechos Humanos, el Protocolo adicional de Derechos Económicos, Sociales y Culturales y efectúa un control de convencionalidad difuso, utilizando los precedentes del caso Almonacid Arellano Vs. Chile y la opinión consultiva OC-23 del 15 de noviembre de 2017 .

Como podemos observar, se trata de una línea jurisprudencial constante, que da cuenta de una mayor intervención judicial por medio de lo que hemos llamado en este texto sentencias estructurales de segunda generación ${ }^{69}$. En efecto, como se puede constatar, con el reconocimiento de personalización jurídica de los ecosistemas en crisis, se garantizaron los derechos fundamentales de los individuos que dependían del ecosistema, emitiendo ordenes complejas que integran a varias

69 Ver ut supra, pie de página 25. 
entidades para orientar y garantizar la protección del ecosistema. Sin embargo, podría constatarse un argumento que progresivamente avanzó en los precedentes citados, a saber: la equidad intrageneracional y la protección de los derechos fundamentales de los individuos que aún no existen. Esta es quizá la subregla que aún está en desarrollo y que con seguridad, pone en cabeza de los Tribunales la responsabilidad de garantizar la habitabilidad y supervivencia de generaciones futuras.

\section{Conclusión}

Este trabajo de investigación da cuenta de la emergencia de ciertas categorías intermedias que protegen a los animales en tanto, se reconoce que cuentan con sustratos neurológicos que permite reconocer en ellos sufrimiento y dolor. De igual forma, la personalidad jurídica e identificación de ecosistemas como sujetos de derecho demuestra una sensibilización notable a la dependencia del ser humano de su entorno, reconociéndolo como ser biológico. Con todo, los avances más notables residen en dos aspectos respectivamente: a los animales se les reconoce protección constitucional contra la crueldad y el maltrato, pero también se registra la emergencia de protección contra la extinción, siendo esto último, una protección a la existencia de las especies. Por su parte, la personalidad jurídica de los ecosistemas se identifica con el derecho de generaciones futuras, reconociendo así, un derecho fundamental a la vida, dignidad, agua y ambiente sano de seres humanos que aún no han nacido.

Las categorías jurídicas analizadas demuestran las tensiones entre el antropocentrismo, el ecocentrismo y el biocentrismo, que cuentan además con una carga ideológica que los ha politizado significativamente. Es quizá esta situación extrajurídica la que puede provocar retrocesos en el reconocimiento de los derechos fundamentales de las futuras generaciones y la protección contra la extinción de especies. En la medida en que todos los seres humanos son biológicos, la fuerte politización del debate jurídico puede resultar absurda, contraintuitiva e irrazonable, pero es una realidad.

Ahora bien, el texto también ha dado cuenta de la intersección entre el biocentrismo y el ecocentrismo, en tanto la existencia de la fauna, la diversidad y la existencia humana confluyen en el entorno y el ambiente sano. Es por ello que, tratándose de un problema global, las categorías jurídicas que han sido objeto de análisis han evolucionado convergentemente, aún cuando no pertenecen a las 
mismas familias jurídicas. En estos casos, podemos estar evidenciando la trascendencia de derechos morales o razonamientos éticos a categorías jurídicas intermedias. Sin embargo, persisten restricciones procesales y sustantivas. En efecto, como se evidenció con una de las tantas excepciones, la Sentencia T-596 de 2017, el laberinto formalista sigue teniendo peso tanto para la protección de ecosistemas y el derecho a la equidad intergeneracional, como para la protección de los seres sintientes. Sustantivamente, es notable el cuidado que ha tenido la Corte en no reconocer derechos a los animales, amparando inclusive prácticas culturales crueles, muy a pesar del reconocimiento intermedio como seres sintientes.

Empero, las Cortes parecerían haber extendido una línea progresiva, mediante las enunciadas sentencias estructurales que se han emitido en el marco de la personalización jurídica de ecosistemas. Cuidándose de declarar un estado de cosas inconstitucionales, las Cortes y los Tribunales constataron que la situación afecta a un número significativo de personas, que ésta es consecuencia de la prolongada omisión de las autoridades en el cumplimiento de sus obligaciones para garantizar los derechos y su solución compromete la intervención de varias entidades de distintos niveles para la protección del ecosistema, y como fin último, del derecho a la existencia, dignidad e igualdad de las generaciones futuras.

\section{Bibliografía citada}

Acevedo, Ana María (2016): "El derecho internacional ambiental en la jurisprudencia de la corte constitucional: Una relación indefinida" en Serie documentos de Trabajo Sociedad Latinoamericana de Derecho Internacional. (Bogotá, Universidad Externado de Colombia).

AguirRe, Jorge Francisco (2015): "The hermeneutics contribution to environmental bioethics faced with the biocentric versus anthropocentric dilemma in the globalization era", en Acta bioethica, (No 21), pp. 237-246.

ArendT, Jeffy y Reznick, David (2008): "Convergence and parallelism reconsidered: what have we learned about the genetics of adaptation?", en Trends in Ecology and Evolution (No 23), pp. 26-32.

Bugallo, Alicia Irene (2005): "Ecología profunda y biocentrismo, ante el advenimiento de la era pos-natural”, en Cuadernos del Sur (No 34) pp. 141-162.

Carducci, Michele; Castillo, Lidia Patricia (2016):"Nuevo Constitucionalismo de la Biodiversidad vs. Neoconstitucionalismo del Riesgo", en Estudos Jurídicos e Políticos, (No 37), pp. 255-283. 
Esponda, F. X. M., y Keinrad, M. B. (2017): "Patrimonio biocultural, políticas públicas y derechos humanos: El caso del Programa Modernización Sustentable de la Agricultura Tradicional", en Méthodos, Revista Electrónica de Investigación Aplicada en Derechos Humanos de la CDHDF ( $\left.\mathrm{N}^{\circ}{ }_{13}\right)$, pp. 56-82.

ESQUIROL, Jorge (2014): Las ficciones del derecho latinoamericano. (Bogotá, Siglo del Hombre Editores).

HsiaO, Elaine (2012): "Whanganui River Agreement- Indigenous Rights and Rights of Nature" en Environmental Policy and law, (No 42) pp. 371-375.

Kennedy, Duncan (2006): "Three Globalizations of Law and Legal Thought: 1850-200o", en D. Trubek \& A. Santos (Eds.), The New Law and Economic Development: A Critical Appraisal (Boston Cambridge University Press) pp. 19.73. López, Diego (2006): El derecho de los jueces: obligatoriedad del precedente constitucional, análisis de sentencias y líneas jurisprudenciales y teoría del derecho judicial. (Bogotá, Ediciones Legis).

Osuna, Néstor (2015): "Las sentencias estructurales. Tres ejemplos de Colombia”, en BAZÁN, Víctor (Ed.) Justicia Constitucional y Derechos Fundamentales (México, Ediciones konrad Adenauer Stiftung) pp. 91-115.

SÁNCHEZ, Germán (2002): "Desarrollo y medio ambiente: una mirada a Colombia”en Revista Economía y Desarrollo, ( $\left.{ }^{\circ} 1\right)$ pp. 79-98.

Saravia, Jaqueline \& Rodríguez, Andrea. (2015). "Los Desplazados Forzados Internos en el Estado de Cosas Inconstitucional, Un asunto pendiente", en Revista Prolegómenos. Derechos y Valores ( $\left.\mathrm{N}^{\circ} 18\right)$ pp. 121-134.

Sarmiento, Juan Pablo (2018): "Cuando el comercio internacional se encontró con el medio ambiente, entre el soft law y la prohibición a las barreras al comercio", en Anuario Colombiano de Derecho Internacional ( $\mathrm{N}^{\circ}$ 11), pp. 187-220. Sarmiento, Juan Pablo (2019): "Protocolo de Montreal y el Convenio de Viena, ¿un caso exitoso en Derecho Internacional de protección global del medio ambiente?", en Revista de Derecho ( ${ }^{\circ}{ }^{52}$ ), pp. vi-xii.

Sarmiento, Juan Pablo (2019b): "La crisis ambiental de la Ciénaga Grande de Santa Marta, Colombia: entre la corrupción, la expansión agrícola y la seguridad alimentaria”, en Estudios Jurídicos sobre Aprovechamiento Sustentable de los Recursos Naturales, aproximación a alternativas jurídicas para la sostenibilidad y seguridad alimentaria, (Barranquilla, Ediciones Uninorte) pp. 62-105. 
Sarmiento, Juan Pablo (2020): "Constitucionalismo Regresivo: Reflexiones en torno al equilibrio ideológico en el Tribunal Constitucional colombiano”, en Revista Vniversitas (Vol. 69 No 142).

Twining, William (2003): "Cartografiar el derecho" en Derecho y globalización

(Bogotá D. C., Ediciones Siglo del Hombre, Uniandes, Instituto Pensar) pp. 173-207.

von Bogdandy, Armin (2015): "Ius Constitutionale Commune en América Latina: una mirada a un constitucionalismo transformador", en Revista Derecho del Estado (No. 34), pp. 3-50. DOI:https://doi.org/10.18601/o1229893.n34.o1.

Zamora,Miguel; Huerta,Arturo; PÉrez,Octavio; Benítez,Griselda; IbaÑEZ,Sergio (2016): "Cambio global: el Antropoceno", en Revista Científica Multidisciplinaria de Prospectiva, (No. 23), pp. 67-75.

\section{Jurisprudencia citada}

Ángela María Maldonado Rodríguez y otros Vs. Ministerio de Medio Ambiente, Fundación Instituto de Inmunología de Colombia y otros (2013), Consejo de Estado, Sala de lo Contencioso Administrativo, Sección Tercera - Subsección C.

Juan Luis Castro Córdoba y Diego Hernán David Ochoa Vs. Ministerio de Ambiente y Desarrollo Sostenible, EPM, Hidroeléctrica Ituango S.A. E.S.P. y otros (2019), Tribunal Superior de Distrito Judicial de Medellín, Sala Cuarta Civil De Decisión

Juan Carlos Alvarado Rodríguez y otros, Vs. Ministerio de Medio Ambiente y otros; Tribunal Administrativo de Boyacá.

Andrea Lozano Barragán, Victoria Alexandra Arenas Sánchez, José Daniel y Félix Jeffry Rodríguez Peña, entre otros, Vs. Presidencia de la República, los Ministerios de Ambiente y Desarrollo Sostenible y de Agricultura y Desarrollo Rural, la Unidad Administrativa Especial de Parques Nacionales Naturales y las Gobernaciones de Amazonas, Caquetá, Guainía, Guaviare, Putumayo y Vaupés (2018), Corte Suprema de Justicia, Sala de Casación Civil.

Luís Domingo Gómez Vs. Fundación Botánica y Zoológica de Barranquilla, la Corporación Autónoma Regional de Caldas, Aguas de Manizales S.A. ESP-, la Unidad Administrativa Especial del Sistema de Parques Nacionales Naturales y el Ministerio de Ambiente y Desarrollo Sostenible (2017), Corte Suprema de Justicia - Sala de Casación Civil y Agraria. 
Juliana Morad Acero y otros, Vs. la Secretaría Distrital de Medio Ambiente de Bogotá, (2014), Acción de tutela, Sentencia T-436, Corte Constitucional.

Guillermo Francisco Reyes González, Pedro Alejandro López Arroyave y Manuel Antonio Avella Mendoza,(2014), Acción Pública de Inconstitucionalidad, Sentencia C-283, Corte Constitucional.

Ricardo María Cañón, actuando en su calidad de Personero de Bogotá D.C.(2016),Acción Pública de Inconstitucionalidad, Sentencia C-467, Corte Constitucional.

Henry Acuña Cordero Vs. la Personería Local de Fontibón, la Alcaldía Local de Fontibón, la Secretaría Distrital de Salud, el Centro de Zoonosis y la Secretaría Distrital de Ambiente de Bogotá, (2016), Acción de tutela, Sentencia T-095, Corte Constitucional.

Laura Juliana Santacoloma Mendez(2019), Acción Pública de Inconstitucionalidad, Sentencia C-045, Corte Constitucional.

Luis Domingo Gómez Maldonado Vs. Fundazoo, a Corpocaldas, a Aguas de Manizales, a la Unidad Administrativa Especial del Sistema de Parques Nacionales Naturales y al Ministerio del Medio Ambiente (2020) Acción de tutela, Sentencia SU-016, Corte Constitucional.

Ángela Viviana Bohórquez Cruz(2005), Acción Pública de Inconstitucionalidad, Sentencia C-1192, Corte Constitucional.

Mónica Beltrán Espitia (2006), Acción Pública de Inconstitucionalidad, Sentencia C-115, Corte Constitucional.

Marta C. Bernal González (2006), Acción Pública de Inconstitucionalidad, Sentencia C-367, Corte Constitucional.

Mohd. Salim vs. State of Uttarakhand \& others (2017), High Court of Uttarakhand at Nainital.

Carlos Andrés Echeverry Restrepo (2010), Acción Pública de Inconstitucionalidad, Sentencia C-666, Corte Constitucional.

Jonathan Ramírez Nieves(2012), Acción Pública de Inconstitucionalidad, Sentencia C-889, Corte Constitucional.

María Cristina Pimiento Barrera, Esperanza Pinto Flórez y Juliana Marcela Chahín del Río, (2017), Acción Pública de Inconstitucionalidad, Sentencia C-041, Corte Constitucional.

Daniel Fernando Gutiérrez Hurtado y Juan Pablo OsorioMarín (2018), Solicitud de nulidad de la Sentencia C-041 de 2017, Auto 547, Corte Constitucional. 
Ramsés Alberto Ruiz Sánchez y otros Vs. el Tribunal Administrativo de Cundinamarca, Sección Primera, Subsección A (2018), Acción de tutela, Sentencia SU-056, Corte Constitucional.

Proceso de revisión previa de constitucionalidad de la Ley 1844 de 2017 "por medio de la cual se aprueba el "Acuerdo de París" (2018), Sentencia C-048. Corte Constitucional Colombiana.

Proceso de revisión de constitucionalidad de la Ley 1892 de 2018, por medio de la cual se aprueba el "Convenio de Minamata sobre el Mercurio", hecho en Kumamoto (Japón) el 10 de octubre de 2013. (2019), Sentencia C-275. Corte Constitucional. Juan Gabriel Rojas López (2010), Acción Pública de Inconstitucionalidad, Sentencia C-595, Corte Constitucional.

Andres Rodriguez Pizarro, (1994), Acción Pública de Inconstitucionalidad, Sentencia C-528, Corte Constitucional.

Luís Miguel Llorente (Grupo de Litigio de Interés Público de la Universidad del Norte Vs. Ministerio de Ambiente y Desarrollo Sostenible (MADS), a la Unidad Administrativa Especial de Parques Nacionales Naturales, a la Procuraduría General de la Nación, a la Fiscalía General de la Nación, a la Policía Nacional de Colombia y otros (2020), Corte Suprema de Justicia, Sala de Casación Civil. 